San Jose State University

SJSU ScholarWorks

Faculty Publications, Meteorology and Climate

Science

Meteorology and Climate Science

December 2014

\title{
Optimal Ranking Regime Analysis of Intra- to Multidecadal U.S. Climate Variability. Part I: Temperature
}

\author{
Eugene C. Cordero \\ San Jose State University, eugene.cordero@sjsu.edu \\ Steven A. Mauget \\ U.S. Department of Agriculture, Lubbock, Texas
}

Follow this and additional works at: https://scholarworks.sjsu.edu/meteorology_pub

Part of the Atmospheric Sciences Commons, Climate Commons, and the Meteorology Commons

\section{Recommended Citation}

Eugene C. Cordero and Steven A. Mauget. "Optimal Ranking Regime Analysis of Intra- to Multidecadal U.S. Climate Variability. Part I: Temperature" Journal of Climate (2014): 9006-9026. https://doi.org/10.1175/ JCLI-D-14-00040.1

This Article is brought to you for free and open access by the Meteorology and Climate Science at SJSU ScholarWorks. It has been accepted for inclusion in Faculty Publications, Meteorology and Climate Science by an authorized administrator of SJSU ScholarWorks. For more information, please contact scholarworks@sjsu.edu. 


\title{
Optimal Ranking Regime Analysis of Intra- to Multidecadal U.S. Climate Variability. Part I: Temperature*
}

\author{
Steven A. MAuget \\ Plant Stress and Water Conservation Laboratory, Agricultural Research Service, U.S. Department of \\ Agriculture, Lubbock, Texas \\ EUGENE C. CORDERO \\ Department of Meteorology and Climate Science, San José State University, San Jose, California
}

(Manuscript received 7 January 2014, in final form 11 September 2014)

\begin{abstract}
The optimal ranking regime (ORR) method was used to identify intradecadal to multidecadal (IMD) time windows containing significant ranking sequences in U.S. climate division temperature data. The simplicity of the ORR procedure's output—a time series' most significant nonoverlapping periods of high or low rankingsmakes it possible to graphically identify common temporal breakpoints and spatial patterns of IMD variability in the analyses of 102 climate division temperature series. This approach is also applied to annual Atlantic multidecadal oscillation (AMO) and Pacific decadal oscillation (PDO) climate indices, a Northern Hemisphere annual temperature (NHT) series, and divisional annual and seasonal temperature data during 18962012. In addition, Pearson correlations are calculated between PDO, AMO, and NHT series and the divisional temperature series. Although PDO phase seems to be an important influence on spring temperatures in the northwestern United States, eastern temperature regimes in annual, winter, summer, and fall temperatures are more coincident with cool and warm phase AMO regimes. Annual AMO values also correlate significantly with summer temperatures along the Eastern Seaboard and fall temperatures in the U.S. Southwest. Given evidence of the abrupt onset of cold winter temperatures in the eastern United States during 1957/58, possible climate mechanisms associated with the cause and duration of the eastern U.S. warming hole periodidentified here as a cool temperature regime occurring between the late 1950s and late 1980s-are discussed.
\end{abstract}

\section{Introduction}

In the coming decades, intradecadal to multidecadal (IMD) temperature regimes associated with low-frequency internal climate mechanisms may rival or even dominate greenhouse warming effects at regional scales (Hawkins and Sutton 2009; Hurrell et al. 2010). Apart from their effects on greenhouse warming, these persistent climate modes may also provide, in principle, the basis for decadal climate prediction efforts such as the Met Office's decadal

\footnotetext{
* Supplemental information related to this paper is available at the Journals Online website: http://dx.doi.org/10.1175/JCLI-D-1400040.s1.

Corresponding author address: Steven A. Mauget, USDA Plant Stress and Water Conservation Laboratory, 3810 4th Street, Lubbock, TX 79415.

E-mail: steven.mauget@ars.usda.gov
}

prediction system (Smith et al. 2007) and decadal hindcast and prediction experiments (Keenlyside et al. 2008; Meehl et al. 2009; Taylor et al. 2012; Kim et al. 2012). Over areas where these mechanisms have significant effects over seasonal periods, they may also provide the basis for seasonal climate forecasts. Past research suggests that many of these climate modes or oscillations have oceanic roots [see Solomon et al. (2011) for a review]. Over North America, the most influential IMD mechanisms appear to be those active over the nearby North Pacific and North Atlantic Ocean basins: that is, the Pacific decadal oscillation (PDO; Mantua et al. 1997; Gershunov and Barnett 1998; Barlow et al. 2001; Wang et al. 2009; Dai 2013) and the Atlantic multidecadal oscillation (AMO; Enfield et al. 2001; McCabe et al. 2004, 2008; Sutton and Hodson 2005; Sutton and Hodson 2007, hereafter SH07; Feng et al. 2011; Kumar et al. 2013; Veres and Hu 2013).

A better understanding of IMD climate modes and their effects over the continental United States-that 
is, their timing, geographic location, and seasonalityrequires that they first be correctly detected in observed or modeled data. Although climate variability can be quasi cyclic and may be intermittent or irregular, some approaches to time series analysis are poorly suited to detecting arbitrary climate variation. Trend fitting, although commonly used in climate studies (Karoly and Wu 2005; Lu et al. 2005; Trenberth et al. 2007; Wang et al. 2009; Hoerling et al. 2010; Mass et al. 2011; Kochendorfer and Hubbart 2010; Hodgkins and Dudley 2011), can be sensitive to the choice of start and end years defining the trend-fitting period (e.g., Hartmann and Wendler 2005; Chapman and Walsh 2007; Lins and Cohn 2011; Kumar et al. 2013). Fourier analysis can detect climate oscillations but is mainly intended to identify relatively continuous variation over the data record's duration. Wavelet analysis (Lau and Weng 1995; Torrence and Compo 1998; Anctil and Coulibaly 2004) can isolate intermittent oscillations by projecting wavelet transforms of varying width onto data over moving time windows. Methods based on moving time windows are likely candidates for analyzing IMD climate modes, as they can potentially detect nonstationary cyclic or regimelike behavior. Previous work here focused on identifying such variation using a method that calculates MannWhitney $Z$ statistics over moving time windows of varying duration. This approach, referred to here as the optimal ranking regime (ORR) method, has been used to identify significant IMD periods in U.S. temperature, precipitation, and streamflow (Mauget 2003a,b, 2004; Cordero et al. 2011) and reconstructed South American snowpack records (Masiokas et al. 2012) and to compare observed and modeled IMD temperature variability over the United States (Mauget et al. 2012; Brown et al. 2012).

In the current work, the ORR method is used to detect IMD variation in U.S. annual and seasonal temperature at the climate division scale. The optimally significant ranking regimes found in U.S. temperature will be compared with regimes found in the ORR analysis of annual AMO, PDO, and Northern Hemisphere temperature (NHT) time series. The simplicity of the ORR algorithm's output makes it possible to graphically identify common breakpoints in time and spatial patterns of variability in the analyses of numerous time series. By using this graphic approach and applying the more conventional test of Pearson's correlation, an additional goal is to provide insight into the influence of the PDO and AMO mechanisms on U.S. temperature during 1896-2012. Mauget and Cordero (2014, hereafter Part II) present similar analyses of U.S. precipitation and streamflow data. Section 2 will describe the climate division data and the data used to form time series of annual AMO, PDO, and NHT values. Section 3 will describe the ORR method and demonstrate it on the annual AMO series. Section 4 will present the ORR results and Pearson correlations of the PDO, AMO, and NHT indices with annual and seasonal climate division temperatures. Section 5 will summarize the results of the section 4 analyses and discuss the origins and duration of the U.S. "warming hole" temperature regime in the latter half of the twentieth century.

\section{Data}

\section{a. U.S. climate division data}

Climate division data (Guttman and Quayle 1996) are derived from monthly cooperative station data reported over 344 climate divisions defined by the National Climate Data Center (NCDC). The data used here were aggregated into a 102-division dataset by the National Oceanic and Atmospheric Administration (NOAA) Climate Prediction Center (CPC), which extends continuously between January 1895 and December 2012. Monthly CPC divisional values were averaged here over annual (January-December), winter [December-February (DJF)], spring [March-May (MAM)], summer [JuneAugust (JJA)], and fall [September-November (SON)] periods. As winter averages are identified with the year in which January and February occurs, these annual and seasonal temperature values are defined for the 18962012 calendar years.

NCDC divisional data after 1930 were calculated via equal-weight averaging of monthly average temperature reported from stations within each climate division. Before 1931, station data were not averaged over divisional areas but were averaged statewide or regionally by the U.S. Department of Agriculture (USDA). Current pre-1931 divisional data values have been estimated from those pre-1931 USDA averages via regression relationships between climate division and statewide averages derived over the 1931-82 period. Guttman and Quayle (1996) report that, although correlations between regression-derived and actual divisional values during 1931-82 are typically above 0.90 , the variances of divisional regression estimates before 1931 are generally less than those of the values after 1930 that were directly averaged from station data.

Averaging station data over dense networks can minimize the effects of network changes as stations are added and retired. Although this can also result in the cancellation of random measurement error, systematic bias might remain. Because the ORR method is based on data rankings it is insensitive to biases that are uniform in time. Observational data biases that vary over time, particularly those that are widely introduced into 
the observing network, are more of a concern. In addition to the 1931 variance discontinuity described above, the number and locations of stations within a climate division's area can vary over the period of record. This changing network composition can lead to artificial inhomogeneities, particularly over climate divisions spanning different climate regimes or with complex terrain. Users are warned (Karl et al. 1983) that the station distribution in mountainous western states was not uniform in time before 1931. As a result, a time-varying bias is possible in early state averages and the pre-1931 divisional values derived from them, although a correction procedure is applied to adjust for that bias (Karl et al. 1983; Guttman and Quayle 1996). Although time of observation bias has been corrected for in divisional temperature averages (Karl et al. 1986), urban warming (Karl and Jones 1989) is a potential source of time-varying bias over areas with developing urban settings, as are the temperature affects associated with gradual changes in land use and land cover (Mahmood et al.2010). Given the extent of the U.S. cooperative station network and its variation over time, we cannot know a priori whether these biases have influenced the rank ordering of the annual or seasonal temperature data considered here. However, if these time-varying biases have influenced that ordering, the ORR-based graphic method might detect the related data effects. For example, in the annual and seasonal temperature ORR analyses (see Figs. 4, 6, 8-10) significant shifts in rankings might be evident in western divisional data before and after 1930 .

\section{b. AMO, PDO, and Northern Hemisphere temperature indices}

Annual and seasonal AMO values for 1896-2012 were averaged from monthly values obtained from the NOAA/Earth Systems Research Laboratory (ESRL; http://www.esrl.noaa.gov/psd/data/timeseries/AMO/). Monthly NOAA/ESRL AMO values were calculated from the SST anomaly (SSTA) analyses of Kaplan et al. (1998) as an area-weighted average of detrended North Atlantic SSTA to $70^{\circ} \mathrm{N}$ during 1856-2012. Yearly and seasonal PDO values were averaged from the Joint Institute for the Study of the Atmosphere and Ocean (JISAO; http://jisao.washington.edu/pdo/ PDO.latest) monthly PDO values. As the monthly JISAO PDO values begin in January 1900, those values were averaged to form an annual PDO time series during 1900-2012 and seasonal time series during 1901-2012. Yearly and seasonal average Northern Hemisphere surface temperature (NHT) during 18962012 was derived from monthly NHT values from the Hadley Centre Climatic Research Unit, version 3 historical temperature dataset (HadCRUT3; Brohan et al. 2006; available at http://www.cru.uea.ac.uk/cru/ data/temperature/HadCRUT3-nh.dat).

\section{The optimal ranking regime method}

The ORR method ranks a time series' data values, samples those rankings over moving time windows of

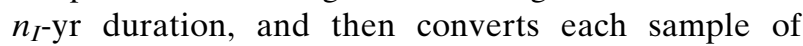
rankings into a Mann-Whitney $U$ statistic (Mann and Whitney 1947). A $U$ statistic for a sample of rankings within an $n_{I^{-}}$-yr time window can be calculated based on the sample's size and rank sum (Mendenhall et al. 1990; Wilks 1995) but can also be understood as the total number of data values outside the sampling window that precede each sample value when all data values are arranged by rank (Hollander and Wolfe 1999). Thus, for a $117-\mathrm{yr}$ time series divided into an $n_{I}=10 \mathrm{yr}$ sample window and $n_{I I}=107 \mathrm{yr}$ outside that window, the highest possible $U$ statistic would occur when the sample contains the 10 highest ranked years $(U=107 \times 10)$. The lowest value would result from a sample containing the 10 lowest ranked years $(U=0 \times 10)$. Randomly sampled sets of 10 rankings produce $U$ statistics that are normally distributed between those two extreme values, with values in the distribution's lower (upper) tail indicating a high incidence of low (high) rankings in a sample. That distribution's mean is equal to the average of the minimum and maximum $U$ values, for example,

$$
\mu_{0}=0.5[(0 \times 10)+(10 \times 107)]=0.5 n_{I} n_{I I},
$$

while the standard deviation can be estimated via the expression (Mendenhall et al. 1990),

$$
\sigma_{0}=\left\{\left[n_{I} n_{I I}\left(n_{I}+n_{I I}+1\right)\right] / 12\right\}^{1 / 2} .
$$

The Gaussian $U$ statistics can be $Z$ normalized using these null parameters, with significantly low (high) $Z$ values indicating a significant incidence of low (high) annual temperature rankings relative to a null hypothesis that assumes random sampling $H_{0}$,

$$
Z_{0}=\frac{U-\mu_{0}}{\sigma_{0}} .
$$

The ORR method's goal is to detect the most significant sequences of low and high rankings in a climate time series. Like other approaches to signal detection, whether it considers a sequence to be significant, as well as the degree of that significance, depends on how noise is defined. The null hypothesis of Eq. (3) holds that a ranking sample is consistent with serially independent white noise. In the ORR procedure a second null hypothesis $H_{1}$ is also considered that specifically tests for 
significant IMD climate regimes. The $H_{1}$ hypothesis holds that a time series contains no low-frequency variability consistent with such regimes. While it might be assumed that the absence of low-frequency climate variation might imply white noise (i.e., $H_{0}$ and $H_{1}$ are equivalent), the ORR method tests that assumption by comparing the outcomes associated with both hypotheses. The null parameters for $H_{1}$ are calculated via a procedure that removes the low-frequency variability from each time series, generates autoregressive (AR) noise processes based on the autocorrelation function of the high-pass residual series, and then calculates $U$ null statistics from the rankings of those noise processes. For each time series and each sample size, the following AR modeling and Monte Carlo procedure calculates $H_{1}$ null parameters $\left(\mu_{1}, \sigma_{1}\right)$, then compares the resulting $Z$ statistics with that derived via Eq. (3) to determine which hypothesis results in the most conservative significance test:

(i) As $H_{1}$ assumes no low-frequency temperature regimes, each time series' low-frequency component was derived via a low-pass Lanczos filter (Duchon 1979) and then subtracted from the data to form a high-pass residual series. As the shortest sampling window considered is $6 \mathrm{yr}$, with a corresponding cyclic period of $\sim 12 \mathrm{yr}$, this filter was assigned a half-power cutoff frequency of $\nu=10^{-1} \mathrm{yr}$.

(ii) Calculate lag 1 autocorrelation values $[\mathrm{AR}(1)]$ from the residual series resulting from step (i).

(iii) Using the step (ii) autocorrelation value, form $\operatorname{AR}(1)$ noise series with lengths equal to that of the time series being tested. Then, adjust the variance of the noise series to agree with that of the data and rank those values.

(iv) From the ranked noise processes resulting from step (iii) calculate appropriate null statistics, which in the previous example would be $U$ statistics derived from nonoverlapping 10-yr segments of each noise series.

(v) Repeat steps (iii) and (iv) until 10000 independent $U$ null statistics are formed, and then calculate the $\mu_{1}$ and $\sigma_{1}$ parameters of the resulting null distribution.

(vi) Use the $\mu_{1}$ and $\sigma_{1}$ parameters to normalize $U$ statistics derived from a sample of data rankings into a corresponding $Z_{1}$ statistic,

$$
Z_{1}=\frac{U-\mu_{1}}{\sigma_{1}}
$$

In the ORR procedure, a sample's $Z$ statistic is assigned based on which normalization, $Z_{0}$ or $Z_{1}$, results in the most conservative significance estimate. These assignments were mainly determined by the relative magnitudes of $\sigma_{0}$ and $\sigma_{1}$. Although the Monte Carlo generated $\mu_{1}$ values typically differ from the corresponding Eq. (1) $\mu_{0}$ value by approximately $0.1 \%, \sigma_{1}$ values generated using 6-45-yr samples drawn from the rankings of the step (iii) noise series are, with few exceptions, smaller than the corresponding Eq. (2) $\sigma_{0}$ values. In those cases $\left|Z_{0}\right|<\left|Z_{1}\right|$, and $Z$ statistics are calculated via Eq. (3). In time series with pronounced low-frequency variation such as the AMO and PDO series, $\sigma_{1}>\sigma_{0}$, resulting in $\left|Z_{1}\right|<\left|Z_{0}\right|$. In those instances, $Z$ statistics are calculated using Eq. (4).

Figures 1a-e demonstrate the ORR procedure applied to the 1896-2012 time series of annual AMO values. Figure 1a shows the annual AMO values, while Fig. $1 \mathrm{~b}$ shows the $Z$ statistics for AMO rankings sampled over running 10 -yr time windows. The horizontal lines in Fig. $1 \mathrm{~b}$ mark the $Z$ statistics negative and positive significance at two-sided $95 \%$ and $99 \%$ confidence levels and a corresponding cool shade-warm shade scheme for showing negative and positive significance at those levels. The colored horizontal lines in Fig. 1c mark the 10-yr ranking regimes shown as negatively or positively significant at a $95 \%$ or better confidence level in Fig. 1b, superimposed on the AMO series. The vertical placement of those lines shows the ranking regime's corresponding $Z$ statistic, as measured by the figure's right-hand axis.

To extend the Fig. 1c test to a wider range of time scales, $U$ and $Z$ statistics are calculated with sampling windows between 6 and $45 \mathrm{yr}$ in length. For each sample size, running $Z_{0}$ and $Z_{1}$ statistics were calculated for each times series and, as described above, $Z$ values were defined by the normalization that resulted in the smallest $Z$ magnitude. Normalizing $U$ statistics into $Z$ statistics allows for significance testing of a particular window size, as in Fig. 1c, and also allows for comparing the significance of $Z$ statistics derived using different window sizes. After the $U$ statistics from each of the running analyses are normalized, the positive and negative $Z$ statistics from all 40 tests that exceeded a two-sided $95 \%$ confidence threshold are combined as in Fig. 1d. Those statistics are then screened for those periods that are optimally significant over nonoverlapping time windows (Fig. 1e). This screening process begins by sorting all significant regime periods by the absolute value of the period's $Z$ statistic $|Z|$ and recording the most significant statistic and its period. Then, the next most significant $|Z|$ statistic with a period that does not overlap with that of the most significant ranking period is recorded. In the Fig. 1e AMO series, these two leading statistics occurred during a 1903-25 cold phase period and a 1931-62 warm 


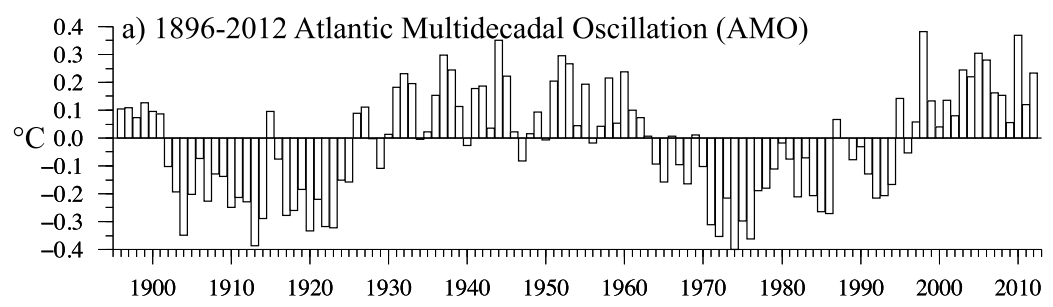

b) Running 10 Year Mann-Whitney Z Statistics of AMO Rankings
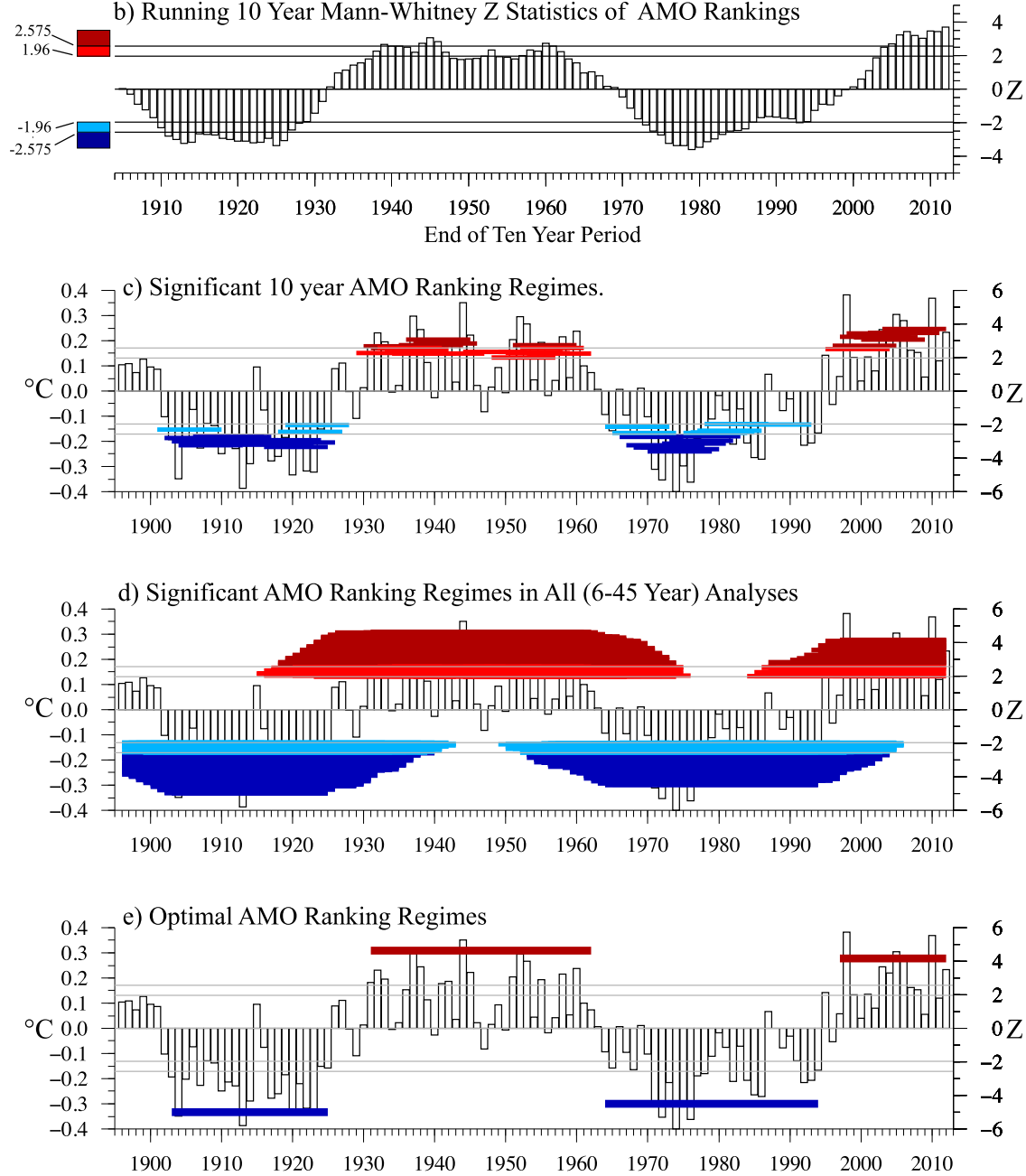

FIG. 1. (a) Time series of annually averaged AMO values during 1896-2012. (b) MannWhitney $Z$ statistics of ranked AMO values sampled over running 10 -yr time windows. Horizontal lines indicate two-sided $95 \%(Z= \pm 1.96)$ and $99 \%(Z= \pm 2.575)$ confidence intervals. (c) As in (a), but with horizontal extent of colored bars showing significant 10-yr cool and warm AMO ranking regimes as indicated in (b). The vertical placement of bars shows the corresponding $Z$ values, as marked by right-hand axis. The color scheme on the left-hand axis shows positive and negative significance at $95 \%$ and $99 \%$ confidence levels. (d) As in (c), but with significant cool and warm phase AMO ranking regimes indicated by running Mann-Whitney $Z$ analyses with 6-, 7-, . . , 45-yr sampling windows. (e) The optimally significant cool and warm phase AMO ranking regimes in (d) occurring over nonoverlapping time windows.

phase period. The ORR algorithm iteratively continues by recording the next most significant $|Z|$ statistic with a period that does not overlap with all previously recorded periods and proceeds until all the significant ranking regimes identified by all the 40 running tests have been considered. In the AMO series, this process identified a 1964-94 cold phase period and a warm phase period during 1997-2012. 

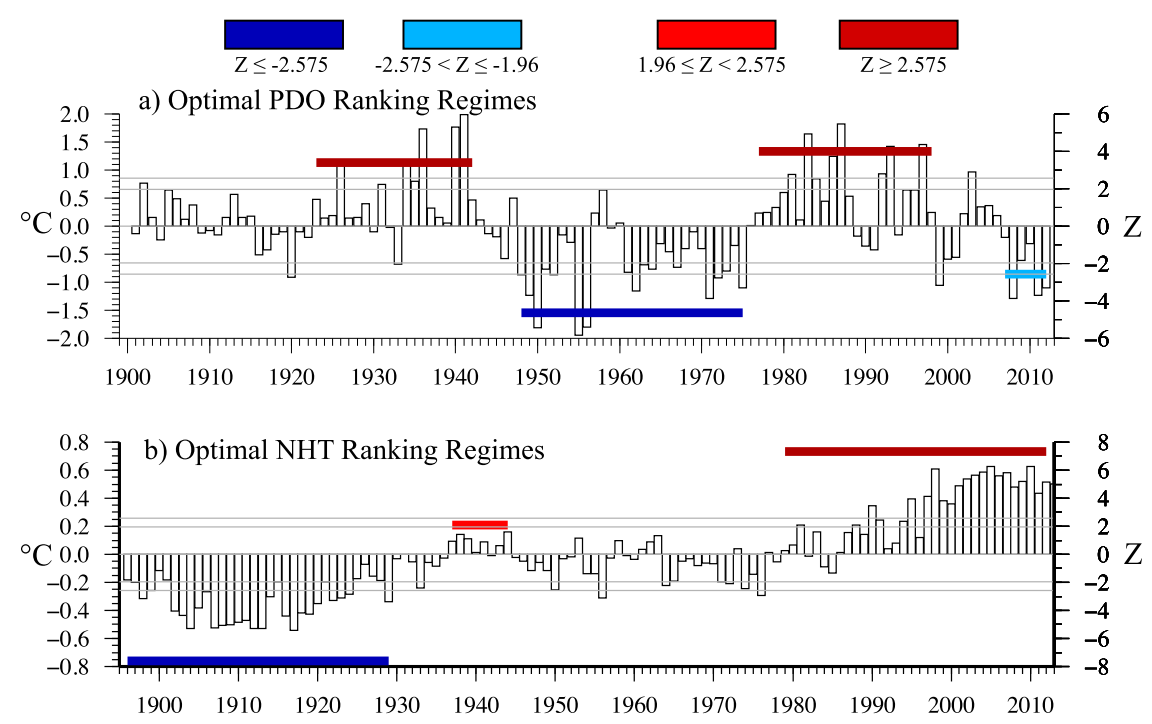

c) AMO, PDO, NHT Cool and Warm Regime Z-lines

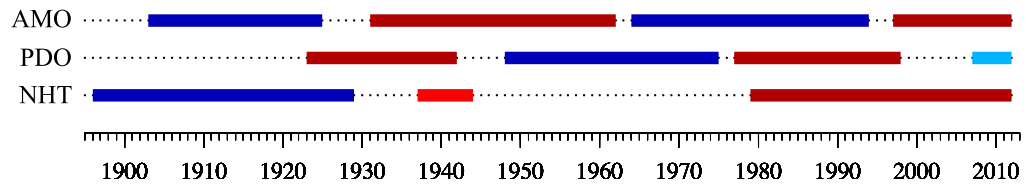

FIG. 2. (a) As in Fig. 1e, but for annually averaged PDO values during 1901-2012. (b) As in Fig. 1e, but for annually averaged NHT during 1896-2012. (c) The optimal AMO, PDO, and NHT ranking regimes plotted as $Z$ lines. The significance shading scheme for $Z$ statistics is shown at the top.

Figure 2a shows the ORR counterpart to Fig. 1e for the annual PDO series. Because the PDO's negative and positive phase are associated with cool and warm SSTA conditions off North America's west coast, the PDO will be considered to be in a cold or warm phase condition to maintain consistency with AMO phase terminology. A cool phase period during 1948-75 followed by a 1977-98 warm regime were separated by the widely described 1976/77 PDO phase shift (Miller et al. 1994; Kerr 1992; Zhang et al. 1997). Before 1948, a warm phase period is identified during 1923-42. After the 1977-98 warm phase period, cool phase conditions were detected during 2007-12. Before 1997, Fig. 2a is roughly consistent with the PDO timeline of Mantua et al. (1997), who identified a warm phase period during 1925-46, a cool phase period during 1947-76, and warm phase conditions after 1976.

Figure $2 \mathrm{~b}$ shows significant NHT regime periods during 1896-2012. Unlike the more cyclic AMO and PDO series the NHT record is dominated by a positive trend. The resulting concentrations of low and high ranked values in the earliest and most recent decades result in a highly significant cool period during 1896-29 $(Z=-7.588)$ and a similarly significant warm period during 1979-2012 ( $Z=7.331)$. Between those two periods the algorithm also identified a significant 8-yr warm period during 1937-44.

The simplicity of the ORR method's results (i.e., a time series' most significant nonoverlapping periods of low and high rankings) allows for the graphic comparison of the results from multiple time series. Given a shading scheme for positive and negative significance like that above Fig. 2, a time series' optimal ranking regimes can be graphed on a single horizontal line referred to here as a $Z$ line. The optimally significant IMD climate regimes from Figs. 1e and 2a,b have been replotted as $Z$ lines in Fig. 2c. If time series are formed from data at different locations (e.g., the annual or seasonal temperatures for the 102 CPC climate divisions), the resulting $Z$ lines can be similarly arranged to plot optimal ranking regimes in time and space.

\section{Continental U.S. temperature: 1896-2012}

The CPC climate divisions in Fig. 3 are identified here with one of three color-coded regions. Although these regions include different U.S. geographical areas, for simplicity they will be referred to as the eastern United States (EUS), central United States (CUS), and western United States (WUS) regions. The choice of these areas 


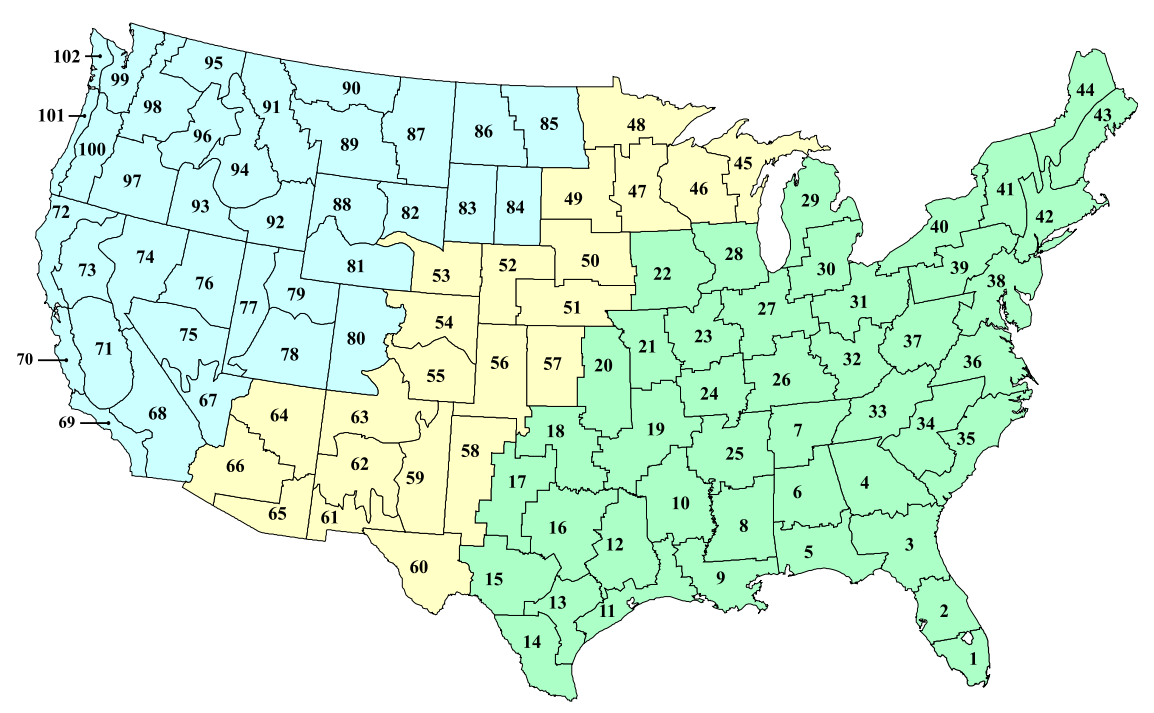

FIG. 3. U.S. climate divisions as defined by the CPC. Green-, yellow-, and blue-shaded regions mark the EUS, CUS, and WUS regions.

was guided by the results of a principal component (PC) analysis of continuous time series of $Z$ statistics derived from gridded U.S. Historical Climatology Network annual temperature data in Mauget et al. (2012). The leading and second PCs of that analysis showed evidence of two dominant low-frequency U.S. temperature modes during 1919-2008. The first PC indicated cool temperature regimes before the late 1960s and warm temperatures after the mid-1980s over the WUS region, while the second PC projected onto a multidecadal oscillation in temperature regimes over the southern part of the green-shaded EUS region in Fig. 3.

\section{a. Annual temperature}

Figure 4 plots the $Z$ lines resulting from the ORR analyses of annual temperature series for each of the 102 climate divisions in Fig. 3. Those $Z$ lines are arranged such that, as the climate division number increases from 1 to 102 , the results of the EUS, CUS, and WUS regions are plotted from bottom to top. The first $Z$ line shows the temperature regimes for south Florida (climate division 1) and the subsequent EUS region $Z$ lines show regimes over the southern, midwestern, and northeastern United States. The CUS $Z$ lines proceed from Michigan's Upper Peninsula (climate division 45) southwestward to western Arizona. The WUS region's $Z$ lines begin in southern Nevada (climate division 67) and then show IMD regimes for climate divisions along a winding path that extends through California, the interior west and northern plains of the United States, and the Pacific Northwest. The last WUS region $Z$ line shows IMD variability for the coast of Washington state (climate division 102). (For comparison, in Figs. 4, 7, and 8-10 the Fig. 2c AMO $Z$ line is plotted below the EUS region climate division $Z$ lines, and the PDO and NHT $Z$ lines are plotted above the WUS region $Z$ lines.)

In Fig. 4, the EUS region's most prominent feature is a pattern of warm regimes during 1920-57 followed by a multidecadal period dominated by cold regimes (Fig. 4a). Pan et al. (2004) noted summer cooling trends over the central United States during 1976-2000 that were opposed to the general tendency to terrestrial warming over the latter half of the twentieth century, and referred to those cooling trends as a warming hole. Although Portmann et al. (2009) and Meehl et al. (2012) associate the warming hole with southeastern U.S. cooling trends, Kumar et al. (2013) demonstrate that the locations and magnitudes of those trends vary with season and the period over which the trend is estimated. Although climate divisions 3-40 in Fig. 4a generally coincide with the warming hole trend regions identified by Portmann et al. (2009) and Meehl et al. (2012), that figure's abrupt shift in temperature regimes suggests a cold transition over the southeastern United States in the late 1950s that may not have been trendlike.

After 1997, the EUS and CUS climate divisions in Fig. 3 were dominated by warm regimes in annual temperature (Fig. 4b), with 1998 indicated as a common breakpoint marking the beginning of warm conditions. That year nearly coincides with the beginning of the most recent AMO warm phase (Fig. 1e). By contrast, 1986 is a common breakpoint marking the onset of recent warm periods in WUS climate divisions (Fig. 4c), which is more coincident with the beginning of the recent NHT warm period in Fig. 2c. Before the mid-1970s, cold regime periods were common in the WUS and CUS 


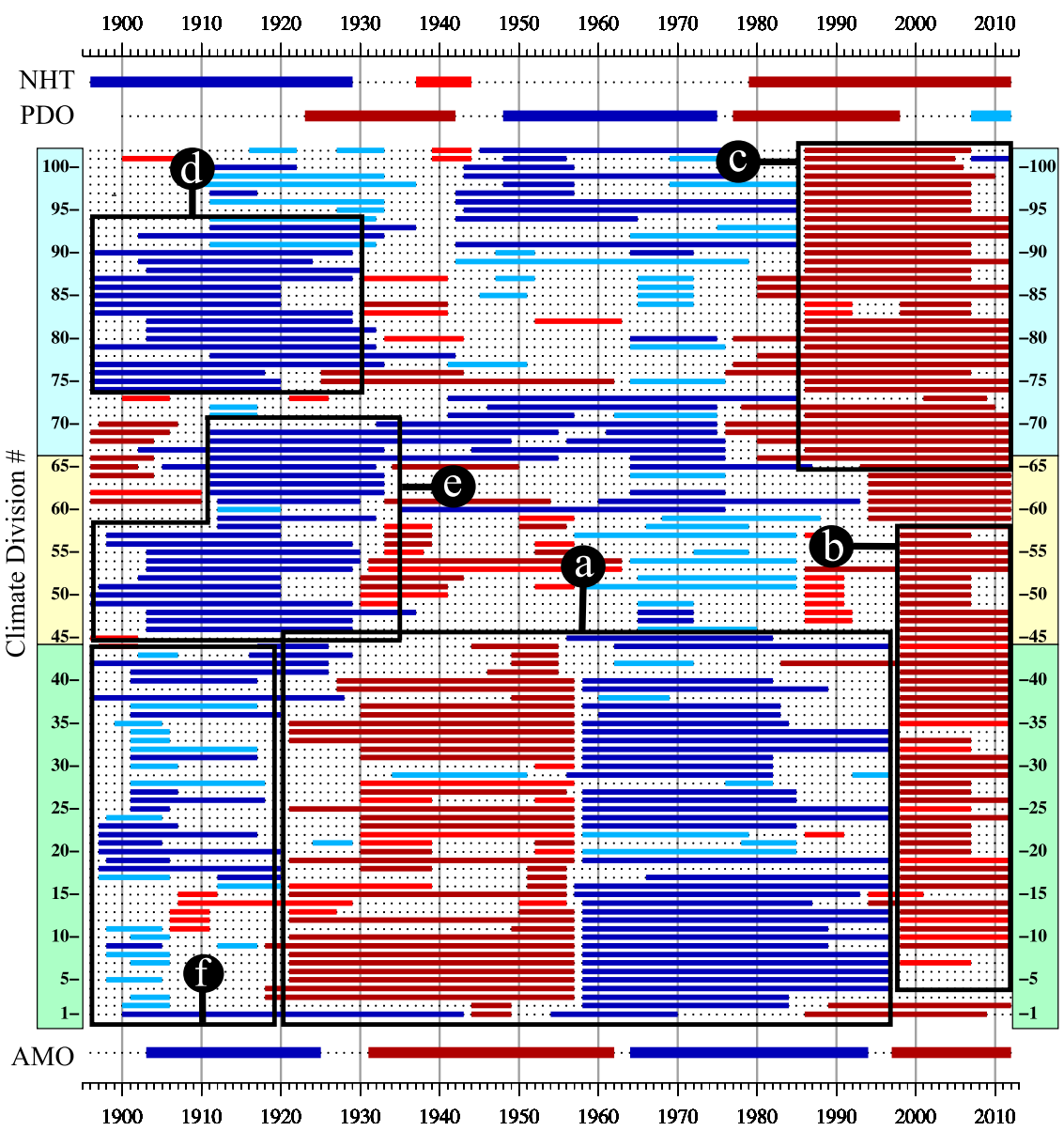

FIG. 4. The $Z$ lines for ORR in the annual temperature time series for each of the 102 climate divisions in Fig. 3. The vertical axis marks the corresponding climate division number. Green-, yellow-, and blue-shaded regions on vertical axis mark $Z$ lines in the EUS, CUS, and WUS regions in Fig. 3. Positive and negative significances at $95 \%$ and $99 \%$ confidence levels are marked by the shading scheme across the top of Fig. 2. The AMO $Z$ line in Fig. 2c is shown below the EUS region climate division $Z$ lines, and the PDO and NHT $Z$ lines are shown above the WUS region $Z$ lines. (a)-(f) The black frames outline IMD temperature regime features discussed in the text.

regions, particularly before the 1930s (e.g., Figs. 4d,e). Although early western cold regimes ended around 1930 - the year that marks the variance discontinuity in the divisional data discussed in section $2 \mathrm{a}$-those regimes also coincide with the cold hemispheric regime during 1896-1929. In the EUS area, less consistent evidence of cold regime periods is evident before 1920 (Fig. 4f).

Figure 4 suggests more cyclic low-frequency temperature variation in the eastern United States relative to the CUS and WUS regions in Fig. 3, which becomes clearer in the ORR analysis of annual temperature series averaged over those areas. Figure 5a is the 1896-2012 time series of area-weighted annual temperature averaged over the WUS climate divisions (WTMP) in Fig. 3, with the series' optimal ranking regimes superimposed as in Figs. 1e and
$2 \mathrm{a}-\mathrm{c}$. Figures $5 \mathrm{~b}$ and $5 \mathrm{c}$ show similar results for annual temperature series averaged over the CUS (CTMP) and EUS (ETMP) climate divisions. Although the WTMP and CTMP series were marked by multidecadal cool periods before 1986 and a warm regime afterward, average EUS temperature shows evidence of alternating temperature regimes: that is, cool periods during 1901-07 and 1958-85 and warm periods during 1921-57 and 19982012. Figure 5d compares the WTMP, CTMP, and ETMP $Z$ lines with those of the PDO, AMO, and NHT series. While the NHT, WTMP, and CTMP series have common cool and warm regimes at the beginning and end of the 1896-2012 period, less agreement is apparent between PDO phase and IMD temperature regimes in the WUS and CUS regions. Although the ETMP and AMO regimes in Fig. 5d are roughly synchronous, before 1998 the 

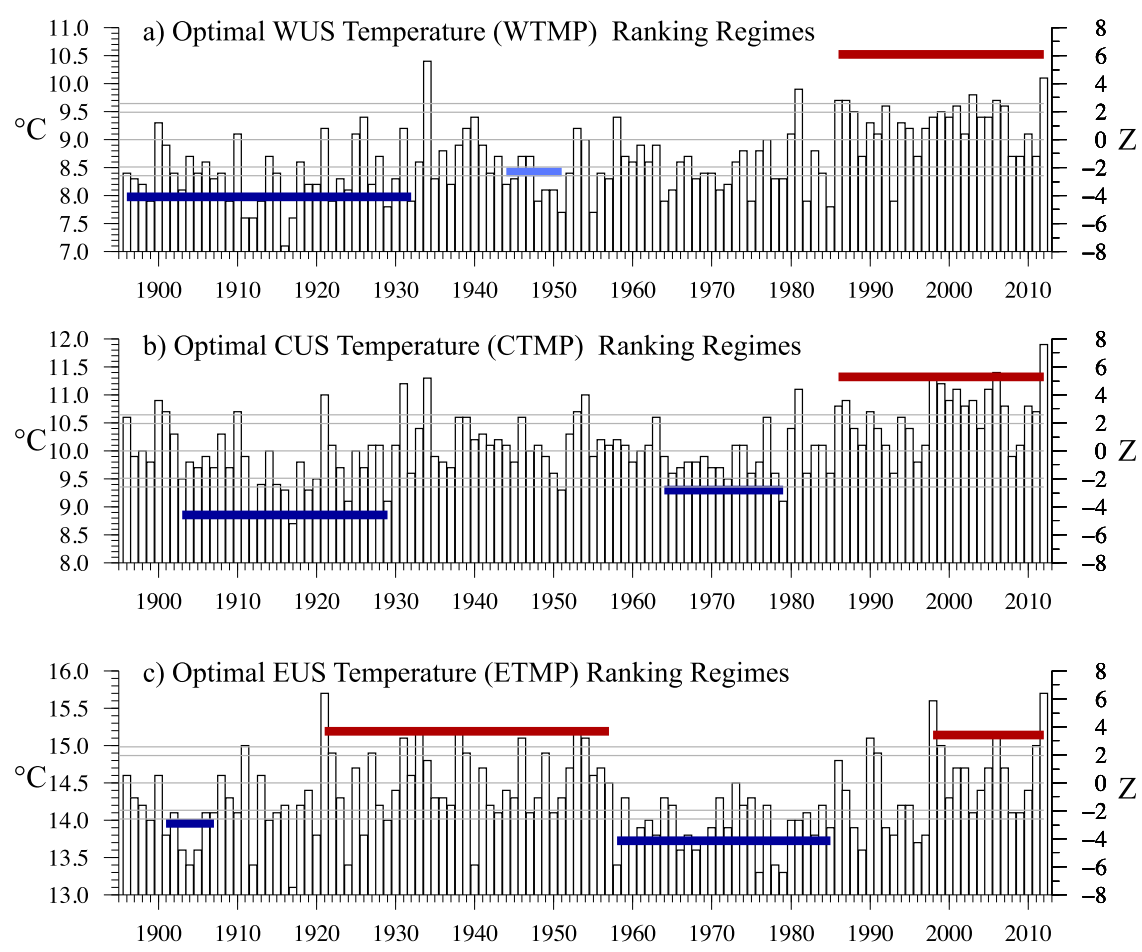

d) NHT, PDO, WTMP, CTMP, ETMP, \& AMO Cool and Warm Regime Periods

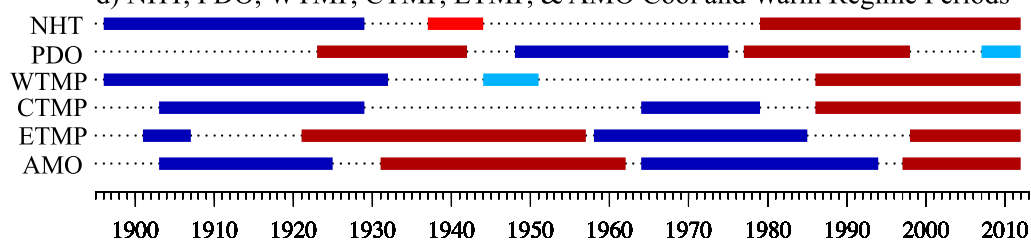

FIG. 5. (a) As in Fig. 1e, but for WTMP spatially averaged over the blue-shaded climate divisions in Fig. 3. (b) As in (a), but for CTMP spatially averaged over the yellow-shaded climate divisions in Fig. 3. (c) As in (a), but for ETMP spatially averaged over the green-shaded climate divisions in Fig. 3. (d) As in Fig. 2c, but for the optimal NHT, PDO, WTMP, CTMP, ETMP, and AMO ranking regimes plotted as $Z$ lines. The significance shading scheme for $Z$ statistics is as found across the top of Fig. 2.

onset of EUS cool and warm regimes consistently precedes those of AMO regimes of similar phase and duration. This leading behavior in land surface temperature relative to nearby oceanic temperature is contrary to the general notion of the ocean as a primary driver in the climate system (Solomon et al. 2011; Hoerling et al. 2011).

\section{b. Winter temperature}

Figure 6 is organized identically to Fig. 4 , with $Z$ lines derived from winter (DJF) climate division temperature rankings. The AMO, PDO, and NHT $Z$ lines are the same as those in Fig. 4, which are based on calendar year rankings. In the EUS region there is a uniform pattern of cold winter periods that begin in 1899 and end in either 1905 or 1906 (Fig. 6a). The warm hole pattern in Fig. 4a is also found in winter temperatures in Fig. 6b. Compared to Fig. 4a, the warm phase of that IMD cycle in winter temperatures shows more uniform evidence of beginning in the early 1920s. However, the $Z$ lines for a number of climate divisions contain warm periods that begin in 1949 or 1950 and end in the mid-1950s (e.g., divisions 29-31 and 37-42), which is the approximate duration of the 1950s drought. In Fig. 6b, many winter cold regimes begin in 1957/58 and end in the mid- to late 1980s (e.g., divisions 3-16), which suggests a duration period for the southeastern warming hole. The onset, duration, and location of warm winter regimes after the mid-1990s in the WUS region is not as clearly defined as those of annual temperature in Fig. 4b. In the U.S. Southwest and California (divisions 67-70), a shift from cold to warm winter regimes roughly coincides with the 


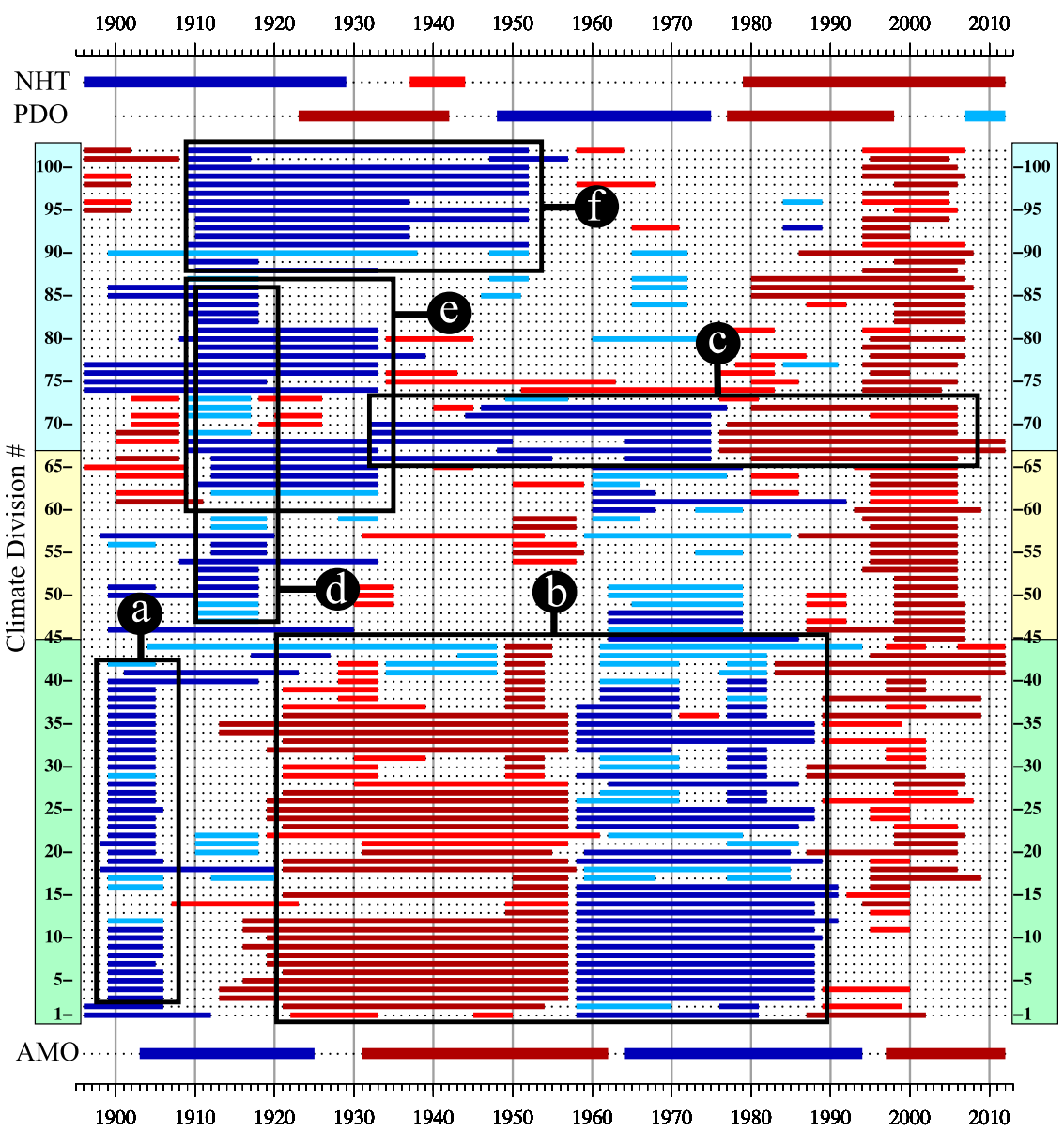

FIG. 6. As in Fig. 4, but for the ORR analysis of winter (DJF) temperature rankings. (a)-(f) The black frames outline the IMD temperature regime features discussed in the text.

1976 PDO phase shift (Fig. 6c). Before 1940, periods marked by cold winters were common in the CUS and WUS regions (Figs. 6d,e). In the northwestern climate divisions, similar cold winter regimes persisted into the early 1950s (Fig. 6f).

Although the ORR method can represent noisy cyclic variation as a series of alternating abrupt regime shifts (e.g., Fig. 1e), past research provides evidence that the multidecadal southeastern winter cold regime in Fig. $6 \mathrm{~b}$ did begin abruptly relative to IMD time scales. After evaluating Pacific-North American (PNA) teleconnection index variability during 1947-87, Leathers and Palecki (1992) noted a sharp increase in the PNA index after 1957 (Fig. 7a) and a concurrent drop in geopotential heights over the southeastern United States (Fig. 7b). This PNA shift is consistent with the corresponding development of an anomalous trough east of the Rocky Mountains and enhanced cold advection into the eastern United States (Leathers et al. 1991). Consistent with that implied circulation shift, Namias (1972) and Dickson and Namias (1976) noted abnormally warm winter conditions at southern and southeastern U.S. stations between the winters of 1947/48 and 1956/57 and an abnormally cold winter regime that began in the winter of $1957 / 58$ and persisted afterward through the 1960s (Fig. 7c and Figs. S1a-c in the supplemental material). ORR analyses of climate division winter temperature show a similar step decrease at that time in significant 10 -yr ranking regimes over those areas (Fig. 7d and Figs. S1d-f). Thus, the warming hole feature found here in annual and winter twentieth-century U.S. temperature, although frequently described in terms of multidecadal trends (Leibensperger et al. 2012; Meehl et al. 2012; Kumar et al. 2013; Pan et al. 2013; Sheffield et al. 2013), seems to have begun in a relatively narrow time window in the late 1950s.

\section{c. Spring temperature}

Figure 8 is the counterpart to Figs. 4 and 6 derived from spring (MAM) divisional temperature rankings. 



Winter mean temperatures at Atlanta, Ga.

d) Significant 10 year Ranking Regimes in Climate Division 4 DJF Temp.

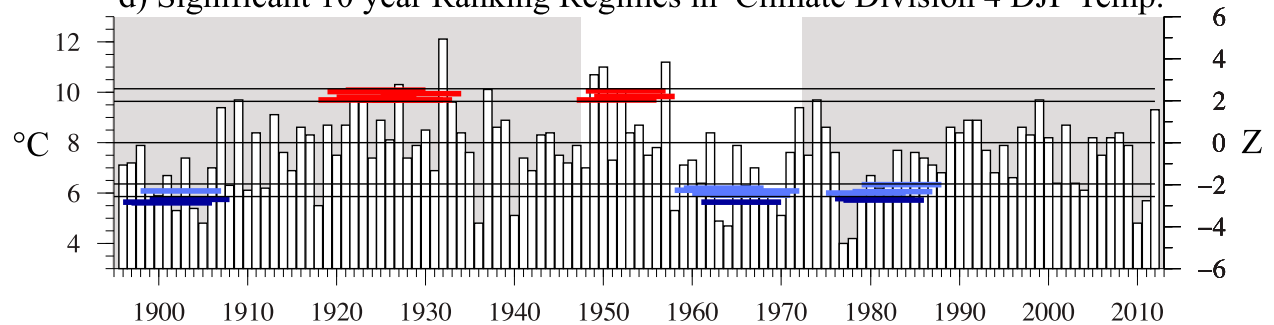

FIG. 7. (a) Monthly PNA index values for the period 1947-87 (Fig. 1a from Leathers and Palecki 1992). (b) Standardized 700-hPa geopotential height anomalies for the southeastern U.S. PNA center of action (Fig. 1d from Leathers and Palecki 1992). Both the (a) and (b) series were smoothed with a 13-month running filter. (c) Winter mean temperatures for Atlanta, GA, for the winters of 1947/48 through 1971/72 (Fig. 1 from Namias 1972). (d) As in Fig. 1c, but for significant 10-yr cool and warm winter (DJF) ranking regimes for the north Georgia climate division (climate division 4). The white region highlights the time frame in (c).

The spring temperature $Z$ lines show a southeastern warming hole cold regime (Fig. 8a) that is less well defined that its winter counterpart in Fig. $6 \mathrm{~b}$ but no previous warm period, as in Figs. $4 \mathrm{a}$ and $6 \mathrm{~b}$. Low-frequency variation in spring temperatures seems more apparent over the WUS and CUS regions and seems roughly synchronous with the PDO in some areas. Before the PDO warm phase period of $1923-42$, there is a clear tendency toward cool spring conditions over western and central climate divisions (Figs. 8b,c). However, during that 20 -yr period, significant runs of low ranked spring temperature in those areas were rare, and some northwestern divisions saw warm regimes (Fig. 8d). During the 1948-76 PDO cool phase, the WUS region was again marked by cool spring regimes (Fig. 8e), which in many cases (e.g., divisions 95, 97, 98, and 100102) coincide or almost coincide with the 1948-75 PDO cool period. Although evident in two groups of $Z$ lines in Fig. 8e, those $Z$ lines indicate cool regimes over a continuous area that includes the southwestern United States and California (divisions 65-73) and the Pacific Northwest (divisions 90-102). After 1976 there 


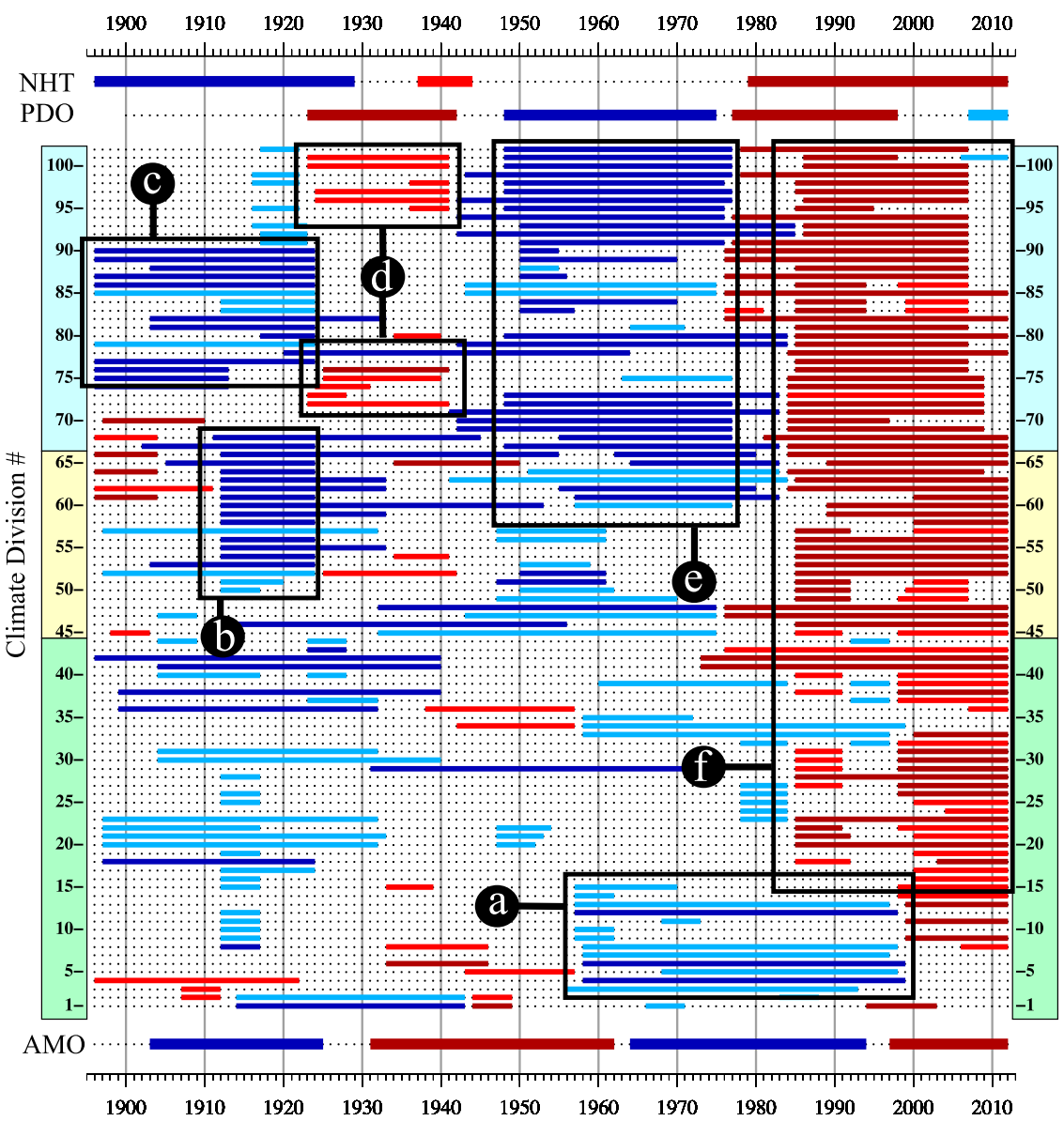

FIG. 8. As in Fig. 4, but for the ORR analysis of spring (MAM) temperature rankings.

(a)-(g) The black frames outline the IMD temperature regime features discussed in the text.

was a return to warm spring conditions during the mid1980 s in the western climate divisions (Fig. 8f), although those warm regimes were much more extensive than those evident in the 1923-42 period (Fig. 8d). Cayan et al. (2001) also note a transition to warmer spring conditions in the western United States during the late 1970s, which they attribute to earlier spring onset. Although Lilly (2001) proposed that that warming might be traced to urban warming effects, previous warm regimes in northwestern spring temperatures during the 1920s and 1930s (Fig. 8d), as well as the high interannual correlations of those temperatures with the PDO described in section 4f, suggest a PDO influence. The 1980s were also, however, a period marked by the onset of warmth in the hemispheric background temperature. The beginning of the recent PDO cool phase period in 2007 coincides with the end of optimally warm spring regimes in many northwestern climate divisions in Fig. 8f (e.g., 87-94 and 96-100) and closely coincides with the beginning of a recent cool spring regime along the Oregon coast (division 101).

\section{d. Summer temperature}

The $Z$ lines in Fig. 9 were derived from summer (JJA) temperature rankings. In that figure, alternating patterns of warm and cool summer regimes are apparent, mainly over the EUS and CUS regions. Before 1960, these warm and cool periods were in approximate phase with warm and cool AMO regimes. Periods marked by a significant incidence of warm summers are apparent in the EUS region (Figs. 9a,b) and the U.S. Southwest and California (Fig. 9c), beginning in 1896 and ending in the first years of the twentieth century. However, during the 1903-25 AMO cold phase period warm IMD summer regimes were rare over most of the continental United States, while significant runs of cool summers were more common (Fig. 9d). In some EUS and CUS climate divisions, these cool periods began in 1902 and ended in the late 1920s before the onset of AMO warm phase conditions in 1931 (e.g., divisions 36-38, 41-43, 46-49, and 52-56). The 1930s "Dust Bowl" drought and the 1950s drought-two of the most persistent and 


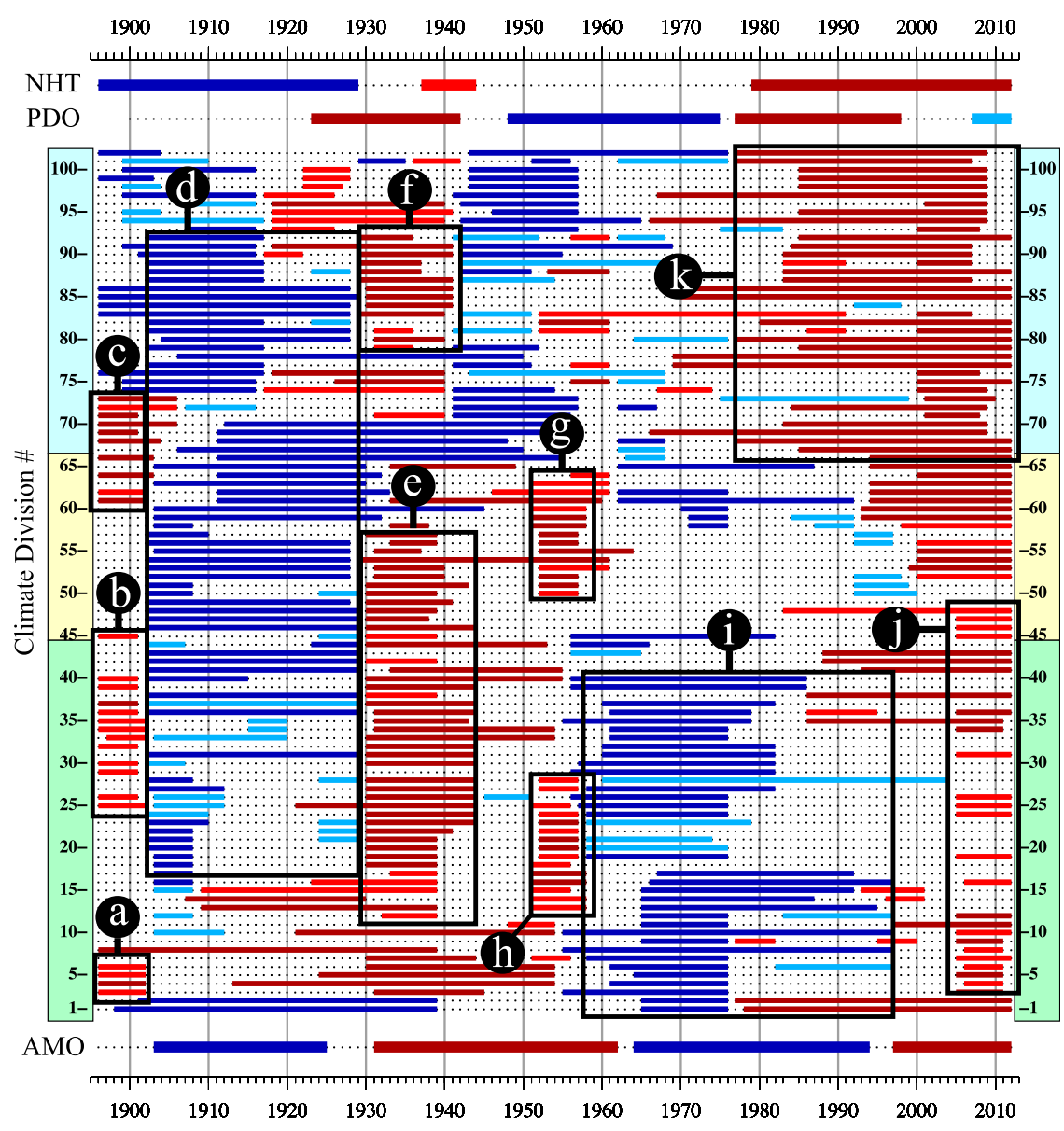

FIG. 9. As in Fig. 4, but for the ORR analysis of summer (JJA) temperature rankings.

(a)-(k) The black frames outline the IMD temperature regime features discussed in the text.

widespread North American droughts of the twentieth century (Mauget 2003b; Cook et al. 2011)—occurred during the AMO warm phase period of 1931-62. In the Fig. 9 analyses, the 1930s drought had a more extensive effect on summer temperatures, with high temperatures over much of the eastern and central regions (Fig. 9e) and the northern plains (Fig. 9f). The summer temperature effects of the 1950s drought are more apparent over the CUS region in Fig. 3 (Fig. 9g) and the westernmost part of the EUS region (Fig. 9h).

After the late 1950s, the EUS $Z$ lines in Fig. 9 show a return to periods with a significant incidence of cool summers (Fig. 9i) that are roughly concurrent with the warm hole period found in annual (Fig. 4a) and winter temperature rankings (Fig. 9b). In some southeastern climate divisions the cool periods begin in the late 1950s (e.g., divisions 19-21 and 23-26). In others, the most significant runs of low ranked summer temperatures began at approximately the same time as the onset of AMO cool phase conditions in 1964 (e.g., divisions 1, 2, 9, and 11-16). Sutton and Hodson (2005) compared the difference in mean JJA temperature over the North Atlantic region as the AMO shifted from warm phase conditions during 1931-60 to cold phase conditions during 1961-90. Over North America a cooling effect was found over the eastern United States, which is consistent with the transition from warm summer regimes in Figs. 9e-h to cool regimes in Fig. 9i. This suggests an AMO influence on southeastern summer temperature, and possibly a role in sustaining the warm hole regime shown in Fig. 4a in annual temperature. However, there is an obvious problem in attributing the $1957 / 58$ climate shift described in section 4a to the onset of cool phase AMO conditions during the early 1960s. That U.S. temperature shift clearly preceded the shift to an AMO cool phase, which is defined here as occurring in 1964 and by Sutton and Hodson (2005) and SH07 as occurring in 1961.

After the 1964-94 AMO cool phase period, warm summer regimes in some climate divisions of the EUS 
region become apparent after the return of AMO warm phase conditions in 1997 (Fig. 9j). A common breakpoint year marking the beginning of these regimes is 2005 , although in some divisions warm summer conditions resumed in the late 1970s (divisions 1 and 2) or the mid- to late 1980s (e.g., divisions 35, 38, 42, and 43). Thus, summer warming in the EUS region seems generally delayed relative to warming in the WUS region in recent decades (Fig. 9k), which is similar to the pattern of recent warming in annual (Figs. $4 b, c)$ temperatures.

\section{e. Fall temperature}

The $Z$ lines of Fig. 10 show the warm and cold regimes in fall (SON) temperature rankings. A clear feature in fall temperatures are cold regimes over EUS and CUS climate divisions that are roughly concurrent with the 1964-94 AMO cold phase period (Fig. 10a). After the shift to AMO warm phase conditions in 1997, fall temperatures in some EUS and CUS climate divisions also see a shift to warm regimes (Fig. 10b) similar to that seen in annual temperatures (Figs. 4b,c). Similar effects on fall temperatures are not apparent during the previous AMO cool phase period of 1903-25 and warm phase period of 1931-62. Although Figs. 10a,b suggest an AMO-related effect on fall temperatures after 1960 in the EUS region, a more consistent — but weaker-effect seems apparent over the CUS and WUS regions. Before 1930, fall conditions show a clear tendency for cool regimes over those climate divisions (Fig. 10c). Between 1930 and the mid-1960s, warm fall regimes, some of multidecadal duration in the central plains (divisions 50 57), are more the norm (Fig. 10d). The late 1960s to the mid-1980s saw a return to predominantly cool fall periods (Fig. 10e). However, the subsequent shift to warm fall conditions in WUS areas in the mid-1980s (Fig. 10f) is more consistent with the onset of the current NHT warm regime. As in the annual (Figs. 4b,c) and summer (Figs. 9j,k) analyses, the shift to warm western fall conditions after 1985 occurred before similar shifts in the EUS region after 1998.

\section{f. PDO, AMO, and NHT correlations with annual and seasonal temperature}

In some cases, the $Z$ lines in Figs. 4, 6, and 8-10 suggest nonstationary relationships between the state of the PDO and AMO and U.S. temperature regimes. For example, after the mid-1960s, fall temperature regimes in the EUS region seem in phase with the AMO (Figs. $10 \mathrm{a}, \mathrm{b})$, whereas there is no evidence of similar behavior before that time. In other cases, more correlative relationships seem apparent: for example, the tendency for warm and cool fall regimes in the WUS and CUS regions to coincide with the AMO (Figs. 10c-e) and for spring temperature in those areas to coincide with the PDO (Figs. 8d,e). While this suggests that those indices might be correlated with temperature in those areas and seasons, the ORR method does not test for how they might significantly covary with divisional temperatures on a year-to-year basis.

Figures 11a-e show Pearson correlations $\rho$ for time series of annual, winter, spring, summer, and fall divisional temperatures (DTMP) versus time series of the concurrent annual and seasonally averaged PDO values during 1901-2012: that is, annual divisional temperatures were correlated with annual PDO values, DJF temperatures were correlated with DJF PDO values, etc. Confidence thresholds for each correlation were calculated via the method of Ebisuzaki (1997). This approach calculated each annual or seasonal time series' Fourier transform, then constructed noise time series of the same duration from the resulting Fourier amplitudes and randomized phase values. Those null series were then correlated with each divisional temperature series 5000 times to form null distributions. The shaded correlations in Fig. 11 are considered significant because they exceed a two-sided $95 \%$ confidence level.

The PDO's U.S. temperature effects are most apparent in positive correlations with annual (Fig. 11a), winter (Fig. 11b), and spring (Fig. 11c) temperature in the WUS region, with higher correlations evident in climate divisions on or near coastal areas. In those figures, negative correlations of lower magnitude are also found over the southeastern United States. Those patterns of opposing U.S. temperature effects during the winter and spring months are broadly consistent with the PDO regressions of Mantua et al. (1997) and the PNA correlations of Leathers et al. (1991). The highest positive correlations are found in spring temperatures in climate divisions $99(\rho=0.65), 101(\rho=0.65)$, and 102 $(\rho=0.68)$. As the PDO's sign reflects the sign of SST anomalies in the northeastern Pacific and along the U.S. West Coast, this suggests the potential for persistent SSTA in these areas as a predictor for spring temperature in the Pacific Northwest. In the summer (Fig. 11e), significant positive correlations are limited mainly to U.S. West Coast climate divisions, while in fall temperatures (Fig. 11f) weak positive correlations are found across a broad band of climate divisions in the Great Plains, the Midwest, and the Northeast.

Figures $11 \mathrm{f}-\mathrm{j}$ show correlations of annual, winter, spring, summer, and fall divisional temperature series versus time series of annual or seasonally averaged AMO values during 1896-2012. Although the PDO correlations of Figs. 11a-e include negative values in some areas, the AMO correlations are consistently positive. In annual temperatures (Fig. 11f), stronger 


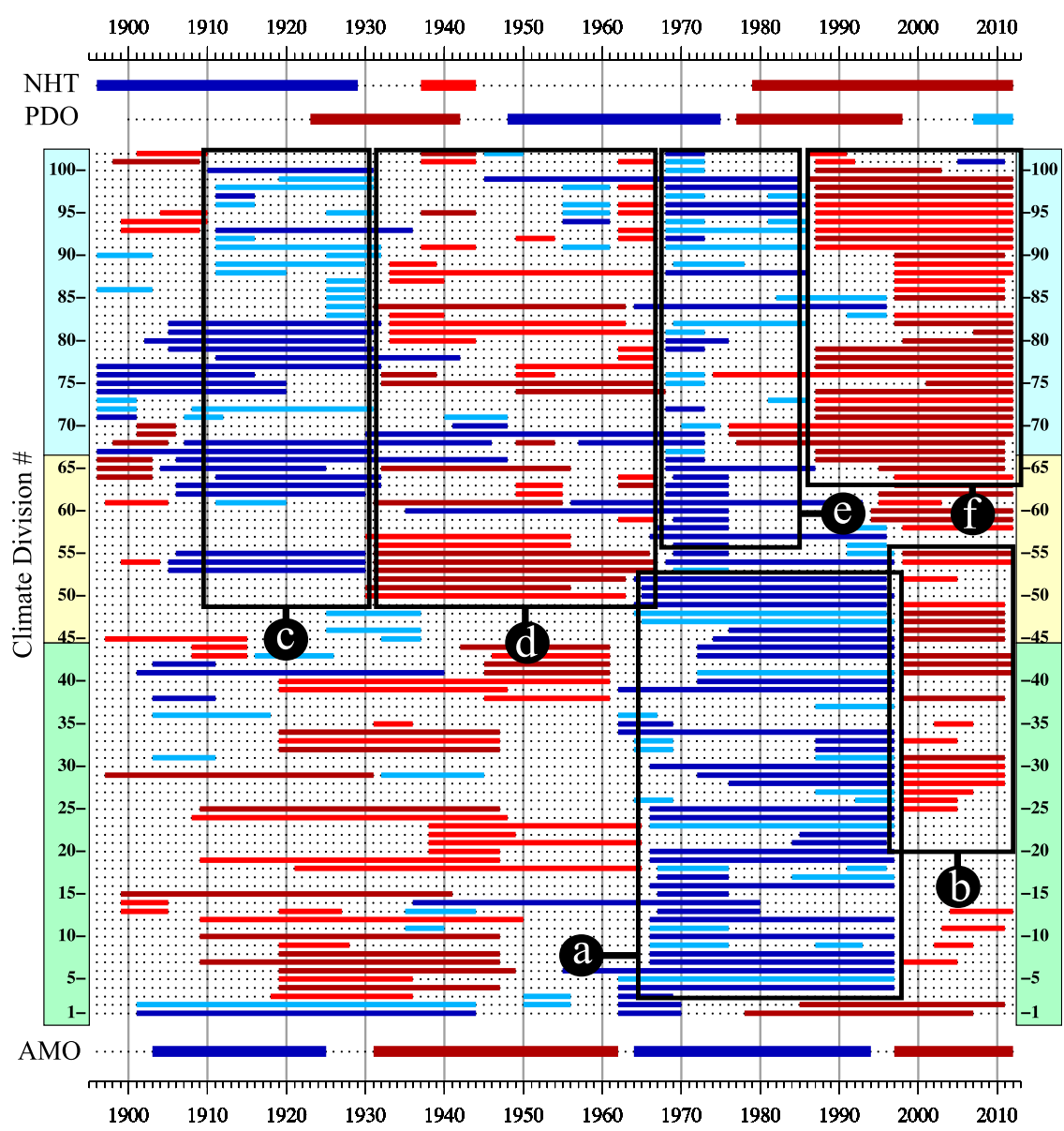

FIG. 10. As in Fig. 4, but for the ORR analysis of fall (SON) temperature rankings. (a)-(f) The black frames outline the IMD temperature regime features discussed in the text.

$(\rho>0.4)$ correlations are limited to northeastern and north-central climate divisions, while winter AMO values significantly correlate with winter temperatures only in Maine's two climate divisions (Fig. 11g). In contrast with the PDO's correlations with spring temperatures in the west, spring AMO correlative effects on spring temperatures are negligible (Fig. 11h). A much clearer effect is found in summer temperatures (Fig. 11i), which shows positive correlations with summer AMO in climate divisions in the EUS region that generally increase as their distance from the Atlantic Ocean decreases. This EUS summer temperature effect is generally consistent with the modeling analyses of SH07, which indicated basinwide variation in North Atlantic SST as a key influence on North American JJA temperature. However, while the SH07 modeling analysis showed that North Atlantic warming had a summer warming effect over relatively broad areas of the United States (their Fig. 3i), the stronger correlations in Fig. 11i are concentrated in the east. The positive correlations in Fig. 11j between fall AMO values and fall temperatures suggest a center of action in the areas of New Mexico and Colorado. Those areas, interestingly, coincide with North American grid areas where North Atlantic warming was found to have a fall warming effect in the $\mathrm{SH} 07$ simulations (their Fig. 31).

Figures $11 \mathrm{k}-\mathrm{O}$ show correlations of annual and seasonal divisional temperature series versus concurrent annual or seasonally averaged NHT values during 1896 2012. Significant positive correlations are found with the annual and seasonal temperature series in most areas of the continental United States outside of the southeast. High correlations with annual NHT $(\rho>0.6)$ are found with annual divisional temperatures in the interior west of the United States, the Rockies, and northern plains (Fig. 11k), and summer NHT is positively correlated with summer temperatures in the interior west of the United States and Rockies (Fig. 11n). Although southeastern temperatures for the most part seem decoupled from the hemispheric background temperature, summer 
$\rho$ (DTMP vs.PDO)

(1901-2012)

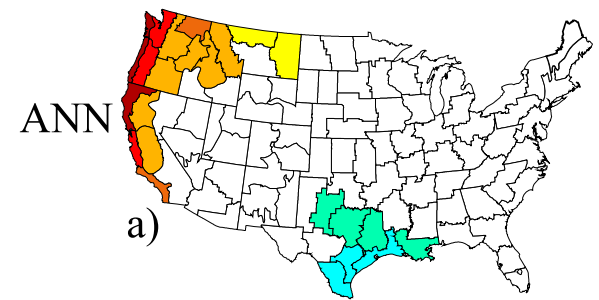

DJF

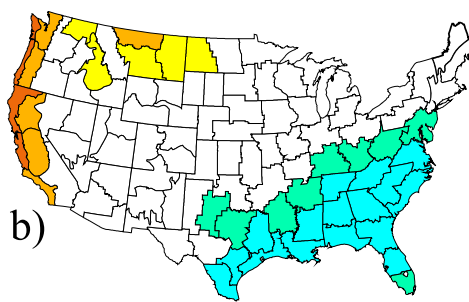

MAM

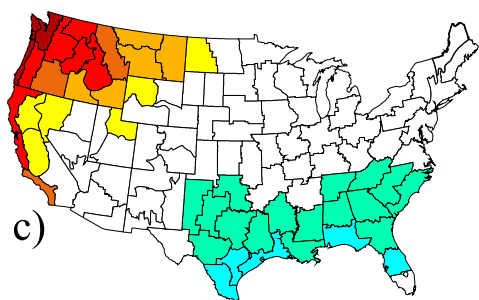

JJA
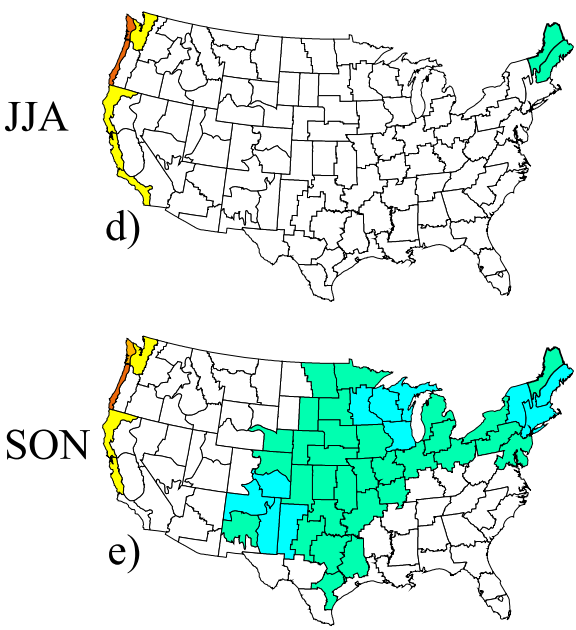

$\rho$ (DTMP vs. AMO)

(1896-2012)
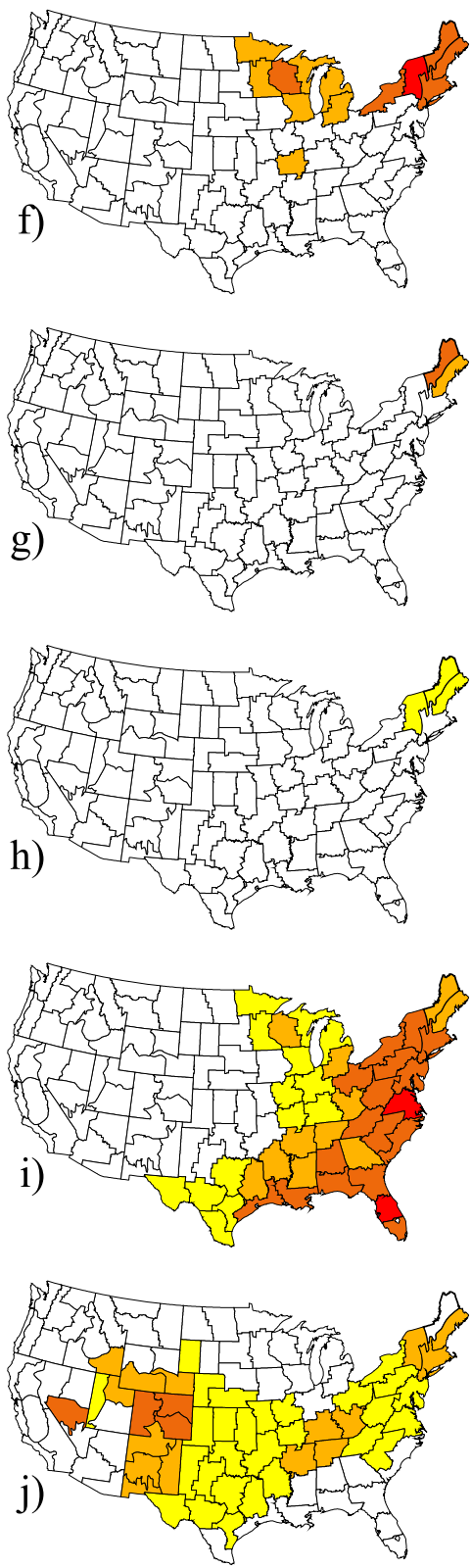

$\rho$ (DTMP vs. NHT)

(1896-2012)

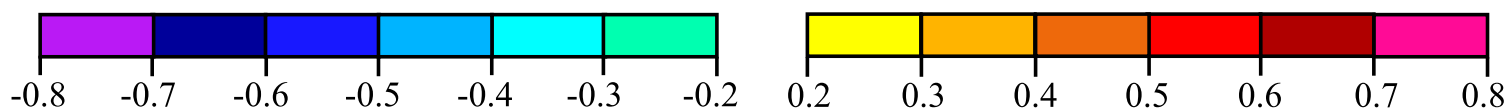

FIG. 11. Pearson correlations of (a) annual, (b) winter, (c) spring, (d) summer, and (e) fall mean DTMP vs concurrent annual or seasonal PDO conditions during 1901-2012. Correlations of (f) annual, (g) winter, (h) spring, (i) summer, and (j) fall mean DTMP vs concurrent annual or seasonal AMO conditions during 1896-2012. Correlations of (k) annual, (l) winter, (m) spring, (n) summer, and (o) fall mean DTMP vs concurrent annual or seasonal NHT values vs during 1896-2012. Shaded climate divisions indicate correlation values significant at a $95 \%$ confidence level. 
temperature in southern Florida (division 1) is strongly correlated $(\rho=0.68)$ with the summer NHT series.

\section{Summary and discussion}

The optimal ranking regime (ORR) method was used to detect intradecadal to multidecadal (IMD) variation in U.S. temperature at the climate division scale during 1896-2012. By calculating Mann-Whitney $U$ and $Z$ statistics from data rankings sampled over moving time windows of varying duration, this method can detect optimally significant ranking sequences in the annual and seasonal temperature time series considered here. Given the possible influence of North Atlantic and North Pacific low-frequency climate modes, IMD regimes in U.S. temperature were compared with ORR-derived regimes in the Atlantic multidecadal oscillation (AMO; Fig. 1e) and the Pacific decadal oscillation (PDO; Fig. 2a), as well as cool and warm regimes in Northern Hemisphere temperature (NHT; Fig. 2b).

The ORR analyses show spring temperature regimes in the western United States that are concurrent with warm and cold PDO regimes (Figs. 8d,e), and spring PDO conditions are found to be strongly correlated with spring temperatures in some Pacific Northwest climate divisions (Fig. 11c). However, more evidence presented here suggests that the AMO may be an important influence on low-frequency temperature variability over the eastern United States. This includes the following:

- The broad similarity of optimal ranking regimes in annual temperature averaged over the eastern U.S. region in Fig. 3 with cyclic AMO regimes, but with a phase discrepancy before 1998 that is difficult to account for in a statistical analysis (Fig. 5c).

- The delay in recent warming in the eastern United States relative to the U.S. West [In annual mean temperature, western warm periods begin in the mid1980s (Fig. 4c) in a manner consistent with the recent NHT warm period (Fig. 2b); in the eastern and central climate divisions in Fig. 3, the most recent warm annual temperature regimes begin in the late 1990s (Fig. 4b), as does the most recent AMO warm period; in the analyses of seasonal temperature, this delayed warming effect is also evident in summer (Figs. 9j,k) and fall temperatures (Figs. 10b,f) but is not found in winter temperatures (Fig. 6); and a more uniform pattern of recent warming over eastern and western climate divisions is evident in spring temperatures (Fig. 8e)].

- Significant Pearson correlations between the summer AMO values and summer temperatures along the Eastern Seaboard (Fig. 11i) and between fall AMO values and fall temperatures in the U.S. Southwest (Fig. 11j).
- The general coincidence of the southeastern U.S. "warming hole" period-identified here as occurring between the late 1950s and late 1980s-with AMO cold phase conditions during 1964-94.

In the annual and winter temperature ORR analyses, a shift from multidecadal warm regimes in the eastern United States before 1958 to a cool period spanning the late 1950s to the late 1980s is clearly apparent in Figs. 4a and $6 \mathrm{~b}$. The latter period is associated here with the cold anomaly in eastern U.S. temperatures referred to by others as the warming hole (Pan et al. 2004; Kunkel et al. 2006; Meehl et al. 2012). This eastern cool regime is somewhat evident in spring (Fig. 8a) and summer (Fig. 9i) but less coherent in space in time than in annual and winter temperatures. The fall temperature analysis (Fig. 10a) shows a similar correspondence between the 1964-94 AMO cool phase period and cool fall conditions in the eastern and central regions in Fig. 3, beginning in the mid-1960s and ending in the mid-1990s. After the warming hole period, the onset of AMO warm phase conditions in 1998 coincided closely with the appearance of warm fall (Fig. 10b) and annual temperature regimes (Fig. 4b) in the EUS and CUS regions in Fig. 3.

As discussed in section $4 \mathrm{~b}$, the relatively abrupt onset of southeastern cold regimes in 1957/58 coincided with a sharp increase in the PNA index (Fig. 7a) and a drop in geopotential heights over the southeastern United States (Fig. 7b) after 1957. As PNA variability has been linked to forcing influences in the central equatorial Pacific (Horel and Wallace 1981; Yarnal and Diaz 1986; Leathers and Palecki 1992; Yu et al. 2007), the coincidence of a PNA shift with the beginning of a North American surface temperature regime suggests the possibility of a tropical Pacific triggering event. In evaluating an ensemble member in phase 3 of the Coupled Model Intercomparison Project (CMIP3) climate model simulations that reproduced the characteristics of the southeastern U.S. warming hole, Meehl et al. (2012) traced the hole's origins to central equatorial Pacific convective anomalies. That modeling result and the observational evidence in Fig. 7 suggests a possible link to the 1957/58 El Niño, which given its widespread effect on Pacific SST, was considered a major warm phase ENSO event by Zhang et al. (1997). Although PDO series in Fig. 2a shows only a brief period of positive annual PDO values during 1957/58, the Pacific SST indices of Zhang et al. (1997) suggest that the oceanic effects of the 1957/58 El Niño event lasted into the early 1960s. Zhang et al. (1997) propose that changes in the Pacific Ocean during that time were comparable to conditions after the 1976/77 PDO shift and differed from that later PDO warm phase period only by its shorter duration. 
Although a circumstantial case might be made for Pacific conditions in the late 1950s and early 1960s as an initial cause of the warming hole period, those conditions cannot account for its duration. In some climate divisions in the eastern region in Fig. 3, the hole's annual and winter cold temperature regimes persisted until the late 1980s (Figs. 4a and 6b). However, numerous ENSO events of both phase occurred between the late 1950s and that time, as did a prominent shift in PDO phase during the mid-1970s. In the initial stage of the warming hole period, eastern U.S. cooling may have been sustained via a surface feedback mechanism outlined by Dickson and Namias (1976):

However, it is suggested that once such a wave pattern becomes established, the thermal condition of the underlying surface may, through identifiable feedback mechanisms at certain key locations, be responsible for encouraging the prolongation or repeated occurrence of the wave pattern as a whole, thus protracting a shortterm climatic change into a longer term climatic regime.

Thus, a shift to positive PNA conditions in the late 1950s may have led to an atmospheric response conducive to cold advection over the eastern United States, with the subsequent surface cooling producing lower geopotential heights over that region (Fig. 7b) and continued positive PNA conditions (Fig. 7a). This positive atmospheric circulation feedback may have in turn supported a persistent regime of cold advection and surface cooling over that region. Evidence for such a feedback was outlined by Namias (1970), who attributed winter cooling over the eastern United States during the 1960s to an amplification of the North American longwave pattern consistent with positive PNA conditions and stronger cold advection into the eastern United States. In the early 1960s the AMO began a transition into a cold phase that lasted until the mid-1990s (Fig. 1e). Sutton and Hodson's (2005) comparison of mean summer land surface temperatures over the North Atlantic region during 1931-60 and 1961-90 indicate a cooling influence as the AMO shifted to a cool phase during the latter period. Circumstantial evidence for an AMO-related link to cooling over the eastern United States during that time seems particularly clear here in fall temperatures (Fig. 10a) and is also found in annual (Fig. 4a), winter (Fig. 6b), spring (Fig. 8a), and summer temperatures (Fig. 9i). Modeling evidence for such a link is found the results of Kumar et al. (2013), who found that CMIP5 models that had higher skill in reproducing the AMO in twentieth-century climate simulations also showed higher skill in reproducing the warming hole. Thus, while the coincidence of events in the tropical Pacific and the onset of the warming hole period in the late 1950s suggests that that period's cooling may have been initially forced from the tropical Pacific, the results of Kumar et al. (2013) suggest it may have been sustained by North Atlantic conditions during 1964-94.

Although Kumar et al. (2013) suggest a central role for the AMO in simulating the warming hole in modeling experiments, they also cite studies that propose diverse theories for its cooling effect, including internally generated variability, multidecadal mechanisms, landatmosphere interactions, regional hydrologic processes, and aerosol effects. Although some of these mechanisms may have played a role in sustaining the hole's multidecadal cooling regime, its abrupt beginning might rule out others as a causal factor. For example, Leibensperger et al. (2012) indicate that radiative cooling due to anthropogenic aerosols over the United States peaked during 1970-90. However, suggesting that the warming hole may have been caused by industrial aerosols seems difficult to support given the contrast between the gradual multidecadal increase in their atmospheric concentrations (Charlson et al. 1992) and the relatively sudden onset of the warming hole period. This does not, however, rule out aerosol effects as a possible sustaining influence during 1970-90. Although the mechanisms linking AMO variation to the warming hole do not seem well established, Schubert et al. (2009) and Feng et al. (2011) note an association between cold phase AMO conditions and wetter conditions over the United States, which suggests the possibility of an AMO-related cooling effect from increased cloudiness. An ORR analysis of streamflow variability in Part II shows an association between cold phase AMO conditions and high streamflow regimes in the eastern United States during the 1970s, which suggests a similar effect during the warming hole's latter stages.

The circumstances of the warming hole period suggests that, in general, IMD climate impacts over the United States may be the complex result of overlapping influences: for example, Pacific triggering events, landatmosphere interactions, multidecadal variation in Atlantic SSTA, and persistent radiative effects associated with either anthropogenic aerosols or cloud cover. Even so, evidence presented here suggests that the AMO may be an important influence on temperature variability over the eastern United States. Research indicating that decadal modes of North Atlantic SSTA may be potentially predictable (Griffies and Bryan 1997; Knight et al. 2005, 2006; Yeager et al. 2012; Robson et al. 2013; Msadek et al. 2014) hints at the possibility for predictive skill in seasonal or decadal forecasts over those areas. As a result, such forecasting, as well as predicting greenhouse warming impacts over the densely populated eastern areas of the United States, may require continued 
focus on ongoing efforts to improve the reproduction of the $\mathrm{AMO}$ in modeling experiments.

Acknowledgments. Monthly AMO values were derived from NOAA ERSST.v3 data provided by the NOAA/Earth System Research Laboratory (Physical Sciences Division), Boulder, Colorado (http://www.esrl. noaa.gov/psd/). All figures were produced using Generic Mapping Tools (Wessel and Smith 1995). The USDA is an equal opportunity provider and employer.

\section{REFERENCES}

Anctil, F., and P. Coulibaly, 2004: Wavelet analysis of the interannual variability in southern Québec streamflow. J. Climate, 17, 163-173, doi:10.1175/1520-0442(2004)017<0163: WAOTIV $>2.0 . \mathrm{CO} ; 2$.

Barlow, M., S. Nigam, and E. H. Berbery, 2001: ENSO, Pacific decadal variability, and U.S. summertime precipitation, drought, and stream flow. J. Climate, 14, 2105-2110, doi:10.1175/ 1520-0442(2001)014<2105:EPDVAU >2.0.CO;2.

Brohan, P., J. J. Kennedy, I. Harris, S. F. B. Tett, and P. D. Jones, 2006: Uncertainty estimates in regional and global observed temperature changes: A new data set from 1850. J. Geophys. Res., 111, D12106, doi:10.1029/2005JD006548.

Brown, P. T., E. C. Cordero, and S. A. Mauget, 2012: Reproduction of twentieth century intradecadal to multidecadal surface temperature variability in radiatively forced coupled climate models. J. Geophys. Res., 117, D11116, doi:10.1029/ 2011JD016864.

Cayan, D. R., M. D. Dettinger, S. A. Kammerdiener, J. M. Caprio, and D. H. Peterson, 2001: Changes in the onset of spring in the western United States. Bull. Amer. Meteor. Soc., 82, 399-416, doi:10.1175/1520-0477(2001)082<0399:CITOOS >2.3.CO;2.

Chapman, W. L., and J. E. Walsh, 2007: A synthesis of Antarctic temperatures. J. Climate, 20, 4096-4117, doi:10.1175/ JCLI4236.1.

Charlson, R. J., S. E. Schwartz, J. M. Hales, R. D. Cess, J. A. Coakley, J. E. Hansen, and D. J. Hofmann, 1992: Climate forcing by anthropogenic aerosols. Science, 255, 423-430, doi:10.1126/science.255.5043.423.

Cook, B., R. Seager, and R. Miller, 2011: Atmospheric circulation anomalies during two persistent North American droughts: 1932-1939 and 1948-1957. Climate Dyn., 36, 2339-2355, doi:10.1007/s00382-010-0807-1.

Cordero, E., W. Kessomkiat, J. Abatzoglou, and S. Mauget, 2011: The identification of distinct patterns in California temperature trends. Climatic Change, 108, 357-382, doi:10.1007/ s10584-011-0023-y.

Dai, A., 2013: The influence of the inter-decadal Pacific oscillation on US precipitation during 1923-2010. Climate Dyn., 41, 633646, doi:10.1007/s00382-012-1446-5.

Dickson, R. R., and J. Namias, 1976: North American influences on the circulation and climate of the North Atlantic sector. Mon. Wea. Rev., 104, 1255-1265, doi:10.1175/1520-0493(1976)104<1255: NAIOTC $>2.0 . \mathrm{CO} ; 2$.

Duchon, C. E., 1979: Lanczos filtering in one and two dimensions. J. Appl. Meteor., 18, 1016-1022, doi:10.1175/ 1520-0450(1979)018<1016:LFIOAT >2.0.CO;2.

Ebisuzaki, W., 1997: A method to estimate the statistical significance of a correlation when the data are serially correlated.
J. Climate, 10, 2147-2153, doi:10.1175/1520-0442(1997)010<2147: AMTETS $>2.0 . C O ; 2$.

Enfield, D. B., A. M. Mestas-Nunez, and P. J. Trimble, 2001: The Atlantic multidecadal oscillation and its relation to rainfall and river flows in the continental U.S. Geophys. Res. Lett., 28, 2077-2080, doi:10.1029/2000GL012745.

Feng, S., Q. Hu, and R. Oglesby, 2011: Influence of Atlantic sea surface temperatures on persistent drought in North America. Climate Dyn., 37, 569-586, doi:10.1007/s00382-010-0835-x.

Gershunov, A., and T. P. Barnett, 1998: Interdecadal modulation of ENSO teleconnections. Bull. Amer. Meteor. Soc., 79, 2715-2725, doi:10.1175/1520-0477(1998)079<2715:IMOET>2.0.CO;2.

Griffies, S. M., and K. Bryan, 1997: Predictability of North Atlantic multidecadal climate variability. Science, 275, 181-183, doi:10.1126/science.275.5297.181.

Guttman, N. B., and R. G. Quayle, 1996: A historical perspective of U.S. climate divisions. Bull. Amer. Meteor. Soc., 77, 293-303, doi:10.1175/1520-0477(1996)077<0293:AHPOUC >2.0.CO;2.

Hartmann, B., and G. Wendler, 2005: The significance of the 1976 Pacific climate shift in the climatology of Alaska. J. Climate, 18, 4824-4839, doi:10.1175/JCLI3532.1.

Hawkins, E., and R. Sutton, 2009: The potential to narrow uncertainty in regional climate predictions. Bull. Amer. Meteor. Soc., 90, 1095-1107, doi:10.1175/2009BAMS2607.1.

Hodgkins, G. A., and R. W. Dudley, 2011: Historical summer base flow and stormflow trends for New England rivers. Water Resour. Res., 47, W07528, doi:10.1029/2010WR009109.

Hoerling, M., J. Eischeid, and J. Perlwitz, 2010: Regional precipitation trends: Distinguishing natural variability from anthropogenic forcing. J. Climate, 23, 2131-2145, doi:10.1175/ 2009JCLI3420.1.

— , and Coauthors, 2011: On North American decadal climate for 2011-20. J. Climate, 24, 4519-4528, doi:10.1175/2011JCLI4137.1.

Hollander, M., and D. A. Wolfe, 1999: Nonparameteric Statistical Methods. 2nd ed. Wiley and Sons, 787 pp.

Horel, J. D., and J. M. Wallace, 1981: Planetary-scale atmospheric phenomena associated with the Southern Oscillation. Mon. Wea. Rev., 109, 813-829, doi:10.1175/1520-0493(1981)109<0813: PSAPAW $>2.0 . \mathrm{CO} ; 2$.

Hurrell, J. W., and Coauthors, 2010: Decadal climate variability, predictability and prediction: Opportunities and challenges. Proc. OceanObs'09: Sustained Ocean Observations and Information for Society, Venice, Italy, European Space Agency, doi:10.5270/OceanObs09.pp.23.

Kaplan, A., M. A. Cane, Y. Kushnir, A. C. Clement, M. B. Blumenthal, and B. Rajagopalan, 1998: Analyses of global sea surface temperature 1856-1991. J. Geophys. Res., 103, 18567 18589, doi:10.1029/97JC01736.

Karl, T. R., and P. D. Jones, 1989: Urban bias in area-averaged surface air temperature trends. Bull. Amer. Meteor. Soc., 70, 265-270, doi:10.1175/1520-0477(1989)070<0265:UBIAAS >2.0.CO;2.

_- M. L. Nicodemus, and R. Quayle, 1983: Statewide average climatic history. National Climate Data Center Historical Climatology Series Rep. 6-1, 35 pp.

_ C. N. Williams, P. J. Young, and W. M. Wendland, 1986: A model to estimate the time of observation bias associated with monthly mean maximum, minimum and mean temperatures for the United States. J. Climate Appl. Meteor., 25, 145-160, doi:10.1175/1520-0450(1986)025<0145: AMTETT $>2.0 . \mathrm{CO} ; 2$.

Karoly, D. J., and Q. Wu, 2005: Detection of regional surface temperature trends. J. Climate, 18, 4337-4343, doi:10.1175/ JCLI3565.1. 
Keenlyside, N. S., M. Latif, J. Jungclaus, L. Kornblueh, and E. Roeckner, 2008: Advancing decadal-scale climate prediction in the North Atlantic sector. Nature, 453, 84-88, doi:10.1038/nature06921.

Kerr, R. A., 1992: Unmasking a shifty climate system. Science, 255 , 1508-1510, doi:10.1126/science.255.5051.1508.

Kim, H.-M., P. J. Webster, and J. A. Curry, 2012: Evaluation of short-term climate change prediction in multi-model CMIP5 decadal hindcasts. Geophys. Res. Lett., 39, L10701, doi:10.1029/ 2012GL051644.

Knight, J. R., R. J. Allan, C. K. Folland, M. Vellinga, and M. E. Mann, 2005: A signature of persistent natural thermohaline circulation cycles in observed climate. Geophys. Res. Lett., 32, L20708, doi:10.1029/2005GL024233.

- C. K. Folland, and A. A. Scaife, 2006: Climate impacts of the Atlantic multidecadal oscillation. Geophys. Res. Lett., 33, L17706, doi:10.1029/2006GL026242.

Kochendorfer, J. P., and J. A. Hubbart, 2010: The roles of precipitation increases and rural land-use changes in streamflow trends in the Upper Mississippi River basin. Earth Interact., 14, doi:10.1175/2010EI316.1.

Kumar, S., J. Kinter, P. A. Dirmeyer, Z. Pan, and J. Adams, 2013: Multidecadal climate variability and the "warming hole" in North America: Results from CMIP5 twentieth- and twentyfirst-century climate simulations. J. Climate, 26, 3511-3527, doi:10.1175/JCLI-D-12-00535.1.

Kunkel, K. E., X.-Z. Liang, J. Zhu, and Y. Lin, 2006: Can CGCMs simulate the twentieth-century "warming hole" in the centra United States? J. Climate, 19, 4137-4153, doi:10.1175/ JCLI3848.1.

Lau, K.-M., and H. Weng, 1995: Climate signal detection using wavelet transform: How to make a time series sing. Bull. Amer. Meteor. Soc., 76, 2391-2402, doi:10.1175/1520-0477(1995)076<2391: CSDUWT $>2.0 . \mathrm{CO} ; 2$.

Leathers, D. J., and M. A. Palecki, 1992: The Pacific/North American teleconnection pattern and United States climate. Part II: Temporal characteristics and index specification. J. Climate, 5, 707-716, doi:10.1175/1520-0442(1992)005<0707 TPATPA $>2.0 . \mathrm{CO} ; 2$.

- B. Yarnal, and M. A. Palecki, 1991: The Pacific/North American teleconnection pattern and United States climate. Part I: Regional temperature and precipitation associations. J. Climate, 4, 517-528, doi:10.1175/1520-0442(1991)004<0517: TPATPA $>2.0 . \mathrm{CO} ; 2$.

Leibensperger, E. M., and Coauthors, 2012: Climatic effects of 1950-2050 changes in US anthropogenic aerosols-Part 2: Climate response. Atmos. Chem. Phys., 12, 3349-3362, doi:10.5194/acp-12-3349-2012.

Lilly, D., 2001: Comments on "Changes in the onset of spring in the western United States." Bull. Amer. Meteor. Soc., 82, 2265-2266, doi:10.1175/1520-0477(2001)082<2265:CAACOC > 2.3.CO;2.

Lins, H. F., and T. A. Cohn, 2011: Stationarity: Wanted dead or alive? J. Amer. Water Resour. Assoc., 47, 475-480, doi:10.1111/ j.1752-1688.2011.00542.x.

Lu, Q. Q., R. Lund, and L. Seymour, 2005: An update of U.S. temperature trends. J. Climate, 18, 4906-4914, doi:10.1175/ JCLI3557.1.

Mahmood, R., and Coauthors, 2010: Impacts of land use/land cover change on climate and future research priorities. Bull. Amer. Meteor. Soc., 91, 37-46, doi:10.1175/2009BAMS2769.1.

Mann, H. B., and D. R. Whitney, 1947: On a test of whether one of two random variables is stochastically larger than the other Ann. Math. Stat., 18, 50-60, doi:10.1214/aoms/1177730491.
Mantua, N. J., S. R. Hare, Y. Zhang, J. M. Wallace, and R. C. Francis, 1997: A Pacific interdecadal climate oscillation with impacts on salmon production. Bull. Amer. Meteor. Soc., 78, 1069-1079, doi:10.1175/1520-0477(1997)078<1069: APICOW $>2.0 . \mathrm{CO} ; 2$

Masiokas, M. H., R. Villalba, D. A. Christie, E. Betman, B. H. Luckman, C. Le Quesne, M. R. Prieto, and S. Mauget, 2012: Snowpack variations since AD 1150 in the Andes of Chile and Argentina $\left(30^{\circ}-37^{\circ} \mathrm{S}\right)$ inferred from rainfall, tree-ring and documentary records. J. Geophys. Res., 117, D05112, doi:10.1029/ 2011JD016748.

Mass, C., A. Skalenakis, and M. Warner, 2011: Extreme precipitation over the west coast of North America: Is there a trend? J. Hydrometeor., 12, 310-318, doi:10.1175/ 2010JHM1341.1.

Mauget, S. A., 2003a: Multidecadal regime shifts in U.S. streamflow, precipitation, and temperature at the end of the twentieth century. J. Climate, 16, 3905-3916, doi:10.1175/ 1520-0442(2003)016<3905:MRSIUS > 2.0.CO;2.

, 2003b: Intra- to multidecadal climate variability over the continental United States: 1932-99. J. Climate, 16, 2215-2231, doi:10.1175/2751.1.

2004: Low frequency streamflow regimes over the central United States: 1939-1998. Climatic Change, 63, 121-144, doi:10.1023/B:CLIM.0000018502.86522.57.

—_, and E. C. Cordero, 2014: Optimal ranking regime analysis of intra- to multidecadal U.S. climate variability. Part II: Precipitation and streamflow. J. Climate, 27, 9027-9049, doi:10.1175/JCLI-D-14-00041.1.

_ - _ , and P. T. Brown, 2012: Evaluating modeled intrato multidecadal climate variability using running MannWhitney $Z$ statistics. J. Climate, 25, 1570-1586, doi:10.1175/ JCLI-D-11-00211.1.

McCabe, G. J., M. A. Palecki, and J. L. Betancourt, 2004: Pacific and Atlantic Ocean influences on multidecadal drought frequency in the United States. Proc. Natl. Acad. Sci. USA, 101, 4136-4141, doi:10.1073/pnas.0306738101.

, J. L. Betancourt, S. T. Gray, M. A. Palecki, and H. G. Hidalgo, 2008: Associations of multi-decadal sea-surface temperature variability with US drought. Quat. Int., 188, 31-40, doi:10.1016/j.quaint.2007.07.001.

Meehl, G. A., and Coauthors, 2009: Decadal prediction: Can it be skillful? Bull. Amer. Meteor. Soc., 90,1467-1485, doi:10.1175/ 2009BAMS2778.1.

, J. M. Arblaster, and G. Branstator, 2012: Mechanisms contributing to the warming hole and the consequent U.S. eastwest differential of heat extremes. J. Climate, 25, 6394-6408, doi:10.1175/JCLI-D-11-00655.1.

Mendenhall, W., D. D. Wackerly, and R. L. Sheaffer, 1990: Mathematical Statistics with Applications. PWS-Kent, 688 pp.

Miller, A. J., D. R. Cayan, T. P. Barnett, N. E. Graham, and J. M. Oberhuber, 1994: The 1976-77 climate shift of the Pacific Ocean. Oceanography, 7, 21-26, doi:10.5670/oceanog.1994.11.

Msadek, R., and Coauthors, 2014: Predicting a decadal shift in North Atlantic climate variability using the GFDL forecast system. J. Climate, 27, 6472-6496, doi:10.1175/JCLI-D-13-00476.1.

Namias, J., 1970: Climatic anomaly over the United States during the 1960's. Science, 170, 741-743, doi:10.1126/science.170.3959.741. 1972: Experiments in objectively predicting some atmospheric and oceanic variables for the winter of 1971-72. J. Appl. Meteor., 11, 1164-1174, doi:10.1175/1520-0450(1972)011<1164: EIOPSA $>2.0 . \mathrm{CO} ; 2$ 
Pan, Z., R. W. Arritt, E. S. Takle, W. J. Gutowski, C. J. Anderson, and M. Segal, 2004: Altered hydrologic feedback in a warming climate introduces a "warming hole." Geophys. Res. Lett., 31, L17109, doi:10.1029/2004GL020528.

— - X. Liu, S. Kumar, Z. Gao, and J. Kinter, 2013: Intermodel variability and mechanism attribution of central and southeastern U.S. anomalous cooling in the twentieth century as simulated by CMIP5 models. J. Climate, 26, 6215-6237, doi:10.1175/JCLI-D-12-00559.1.

Portmann, R. W., S. Solomon, and G. C. Hegerl, 2009: Spatial and seasonal patterns in climate change, temperatures, and precipitation across the United States. Proc. Natl. Acad. Sci. USA, 106, 7324-7329, doi:10.1073/pnas.0808533106.

Robson, J., R. Sutton, and D. Smith, 2013: Predictable climate impacts of the decadal changes in the ocean in the 1990s. J. Climate, 26, 6329-6339, doi:10.1175/JCLI-D-12-00827.1.

Schubert, S., and Coauthors, 2009: A U.S. CLIVAR project to assess and compare the responses of global climate models to drought-related SST forcing patterns: Overview and results. J. Climate, 22, 5251-5272, doi:10.1175/2009JCLI3060.1.

Sheffield, J., and Coauthors, 2013: North American climate in CMIP5 experiments. Part II: Evaluation of historical simulations of intraseasonal to decadal variability. J. Climate, 26, 9247-9290, doi:10.1175/JCLI-D-12-00593.1.

Smith, D. M., S. Cusack, A. W. Colman, C. K. Folland, G. R. Harris, and J. M. Murphy, 2007: Improved surface temperature prediction for the coming decade from a global climate model. Science, 317, 796-799, doi:10.1126/science.1139540.

Solomon, A., and Coauthors, 2011: Distinguishing the roles of natural and anthropogenically forced decadal climate variability. Bull. Amer. Meteor. Soc., 92, 141-156, doi:10.1175/2010BAMS2962.1.

Sutton, R. T., and D. L. R. Hodson, 2005: Atlantic Ocean forcing of North American and European summer climate. Science, 309, 115-118, doi:10.1126/science.1109496.

- and _ 2007: Climate response to basin-scale warming and cooling of the North Atlantic Ocean. J. Climate, 20, 891-907, doi:10.1175/JCLI4038.1.
Taylor, K. E., R. J. Stouffer, and G. A. Meehl, 2012: An overview of CMIP5 and the experiment design. Bull. Amer. Meteor. Soc., 93, 485-498, doi:10.1175/BAMS-D-11-00094.1.

Torrence, C., and G. Compo, 1998: A practical guide to wavelet analysis. Bull. Amer. Meteor. Soc., 79, 61-78, doi:10.1175/ 1520-0477(1998)079<0061:APGTWA>2.0.CO;2.

Trenberth, K. E., and Coauthors, 2007: Observations: Surface and atmospheric climate change. Climate Change 2007: The Physical Science Basis, S. Solomon et al., Eds., Cambridge University Press, 235-336.

Veres, M. C., and Q. Hu, 2013: AMO-forced regional processes affecting summertime precipitation variations in the central United States. J. Climate, 26, 276-290, doi:10.1175/JCLI-D-11-00670.1.

Wang, H., S. Schubert, M. Suarez, J. Chen, M. Hoerling, A. Kumar, and P. Pegion, 2009: Attribution of the seasonality and regionality in climate trends over the United States during 19502000. J. Climate, 22, 2571-2590, doi:10.1175/2008JCLI2359.1.

Wessel, P., and W. H. F. Smith, 1995: New version of the generic mapping tools. Eos, Trans. Amer. Geophys. Union, 76, 329329, doi:10.1029/95EO00198.

Wilks, D. S., 1995: Statistical Methods in the Atmospheric Sciences: An Introduction. Academic Press, 467 pp.

Yarnal, B., and H. F. Diaz, 1986: Relationships between extremes of the Southern Oscillation and the winter climate of the Anglo-American Pacific Coast. Int. J. Climatol., 6, 197-219, doi:10.1002/joc.3370060208.

Yeager, S., A. Karspeck, G. Danabasoglu, J. Tribbia, and H. Teng, 2012: A decadal prediction case study: Late twentieth-century North Atlantic Ocean heat content. J. Climate, 25, 5173-5189, doi:10.1175/JCLI-D-11-00595.1.

Yu, B., A. Shabbar, and F. W. Zwiers, 2007: The enhanced PNA-like climate response to Pacific interannual and decadal variability. J. Climate, 20, 5285-5300, doi:10.1175/ 2007JCLI1480.1.

Zhang, J., J. M. Wallace, and D. S. Battisti, 1997: ENSO-like interdecadal variability: 1900-93. J. Climate, 10, 1004-1020, doi:10.1175/1520-0442(1997)010<1004:ELIV>2.0.CO;2. 
Copyright of Journal of Climate is the property of American Meteorological Society and its content may not be copied or emailed to multiple sites or posted to a listserv without the copyright holder's express written permission. However, users may print, download, or email articles for individual use. 